Atmos. Chem. Phys., 18, 15643-15667, 2018

https://doi.org/10.5194/acp-18-15643-2018

(C) Author(s) 2018. This work is distributed under

the Creative Commons Attribution 4.0 License.

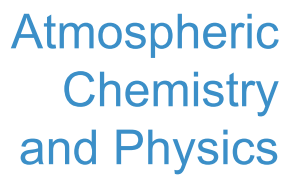

(c) (P)

\title{
Mesoscale fine structure of a tropopause fold over mountains
}

\author{
Wolfgang Woiwode ${ }^{1}$, Andreas Dörnbrack ${ }^{2}$, Martina Bramberger ${ }^{2}$, Felix Friedl-Vallon ${ }^{1}$, Florian Haenel ${ }^{1}$, \\ Michael Höpfner ${ }^{1}$, Sören Johansson ${ }^{1}$, Erik Kretschmer ${ }^{1}$, Isabell Krisch ${ }^{3}$, Thomas Latzko ${ }^{1}$, Hermann Oelhaf ${ }^{1}$, \\ Johannes Orphal $^{1}$, Peter Preusse ${ }^{3}$, Björn-Martin Sinnhuber ${ }^{1}$, and Jörn Ungermann ${ }^{3}$ \\ ${ }^{1}$ Institute of Meteorology and Climate Research, Karlsruhe Institute of Technology, Karlsruhe, Germany \\ ${ }^{2}$ Deutsches Zentrum für Luft- und Raumfahrt, Institut für Physik der Atmosphäre, Oberpfaffenhofen, Germany \\ ${ }^{3}$ Forschungszentrum Jülich, Institute of Energy- and Climate Research, Stratosphere (IEK-7), Jülich, Germany
}

Correspondence: Wolfgang Woiwode (wolfgang.woiwode@kit.edu)

Received: 22 June 2018 - Discussion started: 10 July 2018

Revised: 13 September 2018 - Accepted: 21 September 2018 - Published: 30 October 2018

\begin{abstract}
We report airborne remote-sensing observations of a tropopause fold during two crossings of the polar front jet over northern Italy on 12 January 2016. The GLORIA (Gimballed Limb Observer for Radiance Imaging of the Atmosphere) observations allowed for a simultaneous mapping of temperature, water vapour, and ozone. They revealed deep, dry, and ozone-rich intrusions into the troposphere. The mesoscale fine structures of dry filaments at the cyclonic shear side north of the jet and tongues of moist air entraining tropospheric air into the stratosphere along the anticyclonic shear side south of the jet were clearly resolved by GLORIA observations. Vertically propagating mountain waves with recorded temperature residuals exceeding $\pm 3 \mathrm{~K}$ were detected above the Apennines. Their presence enhanced gradients of all variables locally in the vicinity of the tropopause. The combination of $\mathrm{H}_{2} \mathrm{O}-\mathrm{O}_{3}$ correlations with potential temperature reveals an active mixing region and shows clear evidence of troposphere-to-stratosphere and stratosphere-totroposphere exchange. High-resolution short-term deterministic forecasts of ECMWF's integrated forecast system (IFS) applying GLORIA's observational filter reproduce location, shape, and depth of the tropopause fold very well. The fine structure of the mixing region, however, cannot be reproduced even with the $9 \mathrm{~km}$ horizontal resolution of the IFS, used here. This case study demonstrates convincingly the capabilities of linear limb-imaging observations to resolve mesoscale fine structures in the upper troposphere and lower stratosphere, validates the high quality of the IFS data, and suggests that mountain wave perturbations have the potential to modulate exchange processes in the vicinity of tropopause folds.
\end{abstract}

\section{Introduction}

Tropopause folds are preferred regions of bidirectional stratosphere-troposphere exchange (STE) of mass and trace gases in the middle latitudes (e.g. Holton et al., 1995; Gettelman et al., 2011, and references therein). Their generation is related to cyclogenetically active regions (e.g. Keyser and Shapiro, 1986, and references therein), which develop narrow transition zones where all flow variables become very concentrated. The associated formation of upper-level fronts and surface fronts is mainly driven by the nonlinear selfadvection of evolving Rossby waves. Tropopause folds form preferentially along strong jet streams separating polar or Arctic air masses from those of subtropical origin. The polar front jet (PFJ) is found at middle latitudes and is of ten classified as an eddy-driven jet stream (Held, 1975; Lee and Kim, 2003). Upper-level jet and front systems are prone to the generation of clear-air turbulence, which is an important exchange mechanism for atmospheric constituents across the tropopause (e.g. Shapiro, 1978, 1980; Koch et al., 2005; Kühnlein, 2006; Sharman et al., 2012). Extratropical jet streams are waveguides for planetary Rossby waves (e.g. Dritschel and McIntyre, 2008; Martius et al., 2010). Moreover, they provide a favourable medium for the vertical propagation of internal gravity waves excited in the troposphere (e.g. Preusse et al., 2006; Ern et al., 2018).

Observations of tropopause folds go back to the middle of the last century when their spatial structure was portrayed by observations from radio soundings distributed over large horizontal distances (Reed, 1955; Reed and Danielsen, 1958; historical review by Keyser and Shapiro, 1986). Later, 
and due to the urgent need to explain the exceptional maximum springtime radioactive fallout over North America, the first coordinated aircraft observations were undertaken (Danielsen, 1964, 1968; Danielsen and Mohnen, 1977). Besides atmospheric variables such as wind and temperature, they sampled trace gases, radio nuclei, and aerosols along stacked flight legs through jet streams. Their composites combining potential temperature, potential vorticity, and various constituents enhanced our knowledge about the spatial structure of tropopause folds and the contributions of advection, mixing, and radiation to STE. Melvin Shapiro brought those early conceptual plots by Reed and Danielsen to perfection and designed 2-D cross sections of potential temperature, wind, ozone, and condensation nuclei from flight level and dropsonde measurements (Shapiro, 1980). Basically, these conceptual visualizations provided the base for modified and refined schematics in recent publications (e.g. see Fig. 1 in Gettelman et al., 2011). Later, airborne lidar observations using the differential absorption lidar technique provided valuable insights into the spatial structure of tropopause folds (e.g. Browell, 1987; Ehret, 1999; Flentje, 2005). Airborne observations by one lidar mostly give mixing ratios of one atmospheric constituent (e.g. water vapour or ozone) and aerosol backscatter. Simultaneous airborne lidar observations of ozone and water vapour were only possible on large platforms such as NASA's DC8 (Kooi et al., 2008), and, most recently, on the German research aircraft HALO (High Altitude and Long Range Research Aircraft) during a mission over the North Atlantic (Andreas Schäfler, personal communication, 2018).

Limb observations of various trace gases from a highflying research aircraft were analysed by Weigel et al. (2012) and Ungermann et al. (2013) to investigate their filamentary structure in the summer-time extratropical transition layer near the subtropical jet stream (STJ). The Cryogenic Infrared Spectrometers and Telescope for the Atmosphere New Frontiers (CRISTA-NF) resolved filaments of a spatial scale of less than $800 \mathrm{~m}$ vertically. The diagnostics applied (tracer-tracer correlations of PAN and $\mathrm{O}_{3}$ ) provided the first multi-species 2-D portrait of the inhomogeneous distributions within a tropopause fold extending from about 14 down to $8 \mathrm{~km}$ altitude. Moreover, infrared limb observations are capable of resolving gravity waves in the temperature field (e.g. Preusse et al., 2002; Ungermann et al., 2010). Airborne temperature measurements by the Gimballed Limb Observer for Radiance Imaging of the Atmosphere (GLORIA) in the tomographic mode (Ungermann et al., 2011) were recently used to characterize vertically propagating mountain waves above Iceland (Krisch et al., 2017). GLORIA is a limb-imaging Fourier transform spectrometer for atmospheric research in the upper troposphere and lower stratosphere (UTLS), which was developed as a precursor for future satellite missions (Friedl-Vallon et al., 2014; Riese et al., 2014). Compared to conventional limb-scanning instruments (e.g. Fischer et al., 2008), GLORIA's limb-imaging technique enables much higher sampling rates as all vertical viewing angles associated with a set of atmospheric parameter profiles are measured at the same time.

The horizontal viewing characteristic of GLORIA plays an important role. In cases of horizontally elongated features (i.e. several hundreds of kilometres) such as tropopause folds along the jet stream, the along-track sampling of GLORIA can resolve vertical cross sections in high detail by choosing flight tracks perpendicular to the jet axis. Thereby, GLORIA's low horizontal direction resolution along the line of sight is directed along the elongated atmospheric feature, while the dense along-track sampling is exploited to resolve structures across the jet axis.

In the past, temperature in tropopause folds along the vertical direction was observed at flight level and by dropsondes underneath. Simultaneous in situ measurements of both trace gases and temperature have not been applied up to now to characterize the mesoscale fine structure of tropopause folds. CRISTA-NF observations in July 2006 (Weigel et al., 2012) provided a first coarse perspective of a tropopause fold using this combination of parameters. Here, we present GLORIA airborne observations of temperature, water vapour, and ozone taken simultaneously during two passages of a tropopause fold located over northern Italy on 12 January 2016 in unprecedented quality. GLORIA was deployed on board the HALO during the merged campaigns POLSTRACC (POLar STRAtosphere in a Changing Climate), GW-LCYCLE II (Investigation of the life cycle of gravity waves), and SALSA (Seasonality of Air mass transport and origin in the Lowermost Stratosphere using the HALO Aircraft), in the following abbreviated as PGS. Goals of the PGS campaign were atmospheric and chemical observations related to the Arctic stratospheric polar vortex, gravity waves, and the seasonality of air mass exchange in the UTLS.

GLORIA observations along two extended legs of the research flight over northern Italy reveal the existence of a deep stratospheric intrusion wrapping around the PFJ. At the same time, mountain waves excited by the strong low-level flow over the Apennines propagated vertically from the troposphere into the stratosphere. Both the south- and northbound flight legs were oriented nearly perpendicularly to the axis of the PFJ. Therefore, GLORIA probed the tropopause fold with a propitious viewing geometry pointing nearly parallel into the elongated, zonally oriented jet stream. Low water vapour and high ozone volume mixing ratios were observed inside the tropopause fold. Additionally, mountainwave-induced temperature anomalies in the vicinity of the PFJ and the tropopause fold could be captured.

Admittedly, observations of interactions of jet streams and, in particular, tropopause folds with gravity waves are sparse (e.g. Buss et al., 2004; Koch et al., 2005). Thus, GLORIA's airborne observations presented in this paper have the potential to enhance our knowledge about tropopause folds interfering with vertically propagating mountain waves. With a view on exchange processes between stratosphere and tro- 
posphere, observations of gravity waves interfering with jet streams and developed tropopause folds are of particular interest. Especially in cases of widespread mountain wave excitation above large mountain ranges, mountain wave-jet stream interactions may significantly affect mixing processes associated with tropopause folds. Most recently, Heller et al. (2017) combined different methods to quantify the location, direction, and irreversibility of the water vapour transport during a strong mountain wave event during the Deep Propagating Gravity Wave Experiment (Fritts et al., 2016). Both large positive and negative vertical water vapour fluxes were detected at flight level above and in the lee of the Southern Alps of New Zealand. Tracer-tracer correlations of water vapour to ozone were used to indicate the vertical transport followed by irreversible mixing of water vapour. Their analysis was based on in situ measurements providing tracer-tracer correlations dependent on potential temperature at flight levels; see their Fig. 8. Here, GLORIA observations offer the possibility to construct tracer-tracer correlations and to present them as function of potential temperature at different altitudes below the flight path for the first time.

Nowadays, numerical weather prediction (NWP) models such as the Integrated Forecast System (IFS) of the ECMWF are capable of simulating tropospheric and stratospheric dynamics including tropopause folding and gravity waves with high spatial and temporal resolution (e.g. Preusse et al., 2014; Dörnbrack et al., 2017, references therein). Detailed studies using observations from particular field campaigns or from operational ground-based or satellite sensors are required to validate gravity wave parameterizations of numerical weather forecast systems and models for climate projection (Fritts and Alexander, 2003; Alexander et al., 2010; Geller et al., 2013; Fritts et al., 2016). As we use linear limb observations (i.e. viewing perpendicular to the flight path, without azimuth panning), the IFS data may be interpolated directly at the tangent points. However, in the case of confined local features (i.e. several tens to a few hundreds of kilometres) such as mountain-wave-induced temperature modulations, GLORIA's observational filter, i.e. its smoothing characteristics in the domain along viewing direction must be characterized and applied to the IFS data for a meaningful comparison (Ungermann et al., 2011). Here, the IFS data are folded with GLORIA-specific observational filters for water vapour $\left(\mathrm{H}_{2} \mathrm{O}\right)$ and temperature $(T)$ for quantitative comparisons with the GLORIA data.

Altogether, combining GLORIA data, 1-hourly short-term deterministic IFS forecasts, and in situ observations, we analyse how realistically the IFS reproduces the observations. Furthermore, we discuss the tropopause fold-mountain wave interference and implications with respect to stratospheretroposphere exchange. The paper is structured around the following research questions:

- Do the GLORIA observations of water vapour, ozone, temperature, and potential temperature follow the ac- cepted conceptual models of tropopause folds? How do mountain waves modify the temperature and trace gas distribution?

- Can active mixing regions and STE be identified by means of the infrared limb sounding? Where are they located with respect to the tropopause fold?

- How do high-resolution IFS data compare with the observations? Do observational filters from GLORIA applied to the IFS data improve the comparison with the measurements?

Section 2 describes the data and the methodology to analyse them. Section 3 summarizes the meteorological situation under which the observations took place. Section 4 presents GLORIA data and compares the observations in the vicinity of the aircraft with the flight-level in situ data and selected vertical profiles with one available radiosonde sounding. The core results of the paper are presented in Sect. 5, which considers the mesoscale fine structure of the observed tropopause fold, the mountain-wave-induced temperature fluctuations, and the mixing across the tropopause. Section 6 concludes the paper.

\section{Methodology}

\subsection{GLORIA observations}

GLORIA is a cryogenic limb-imaging spectrometer deployed on board high-altitude aircraft (Friedl-Vallon et al., 2014; Riese et al., 2014). Measurements are performed in limb mode (Fig. 1) to the right-hand side of the flight track. Using 128 vertical $\times 48$ horizontal pixels of a $\mathrm{HgCdTe}$ detector, GLORIA passively observes the thermal radiation of the atmosphere in the spectral range from 780 to $1400 \mathrm{~cm}^{-1}$. The pointing of GLORIA is stabilized using a gimballed frame, aided by an inertial navigation system. During each interferometer sweep, GLORIA records data cubes of interferograms with all pixels simultaneously. Thereby, the detector rows correspond with limb-viewing geometries with tangent altitudes typically between $\sim 5 \mathrm{~km}$ and flight level. In post-flight data processing, spectra of the detector rows within each data cube are binned to reduce uncertainties. The spectra are quantitatively calibrated using in-flight blackbody measurements (Kleinert et al., 2014).

GLORIA can be operated with different spectral sampling rates. Thereby, a higher spectral sampling results in a lower along-track sampling. Here, we use measurements in highspectral-resolution mode ("chemistry mode") with a spectral sampling of $0.0625 \mathrm{~cm}^{-1}$. The resulting apodized spectral resolution of $0.121 \mathrm{~cm}^{-1}$ (full width at half maximum) is particularly useful for resolving weak and narrow spectral signatures of minor species. In this measurement mode, one data cube resulting in one vertical sequence of calibrated 


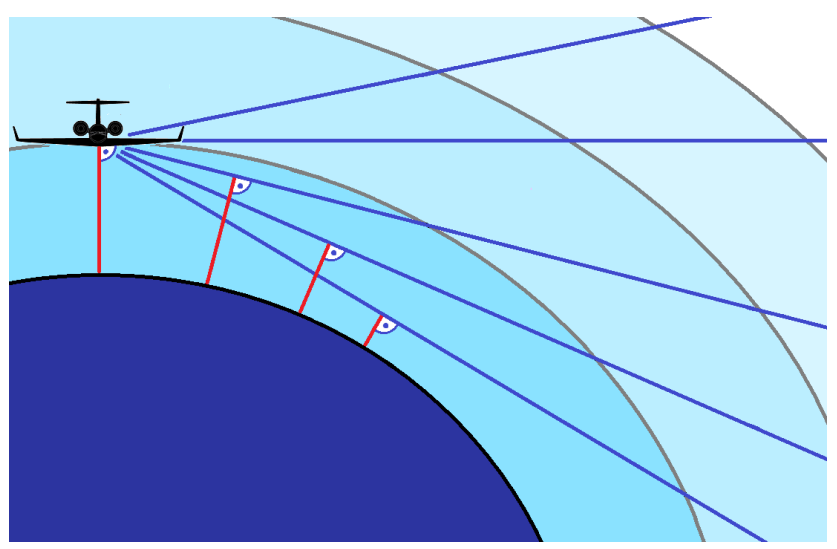

Figure 1. Illustration of GLORIA observation geometries (blue lines) with the carrier HALO moving away from the reader. Limb observations are characterized by their tangent points, where the line of sight is closest to the earth surface (red lines). Low tangent points are situated further away from the observer than high tangent points. The regions around the tangent points contribute the major part of the information derived in atmospheric parameter retrievals. Upward viewing observations have no tangent points along the line of sight and contribute limited information on the scenario above the flight track.

spectra is recorded within $13 \mathrm{~s}$. This corresponds with a net along-track sampling of $\sim 3 \mathrm{~km}$.

The retrieval of atmospheric parameters from the highspectral-resolution mode observations during PGS and their validation are reported by Johansson et al. (2018). Prior to the retrieval, the binned spectra are cloud-filtered according to the cloud index method by Spang et al. (2004). A variable threshold value is applied, increasing linearly from 3.0 for the lowest limb views to 1.8 at flight altitude. For the retrievals, the radiative transfer model KOPRA (Karlsruhe Optimized and Precise Radiation transfer Algorithm; Stiller et al., 2002) is used in combination with the inversion algorithm KOPRAFIT (Höpfner et al., 2001). Temperature is retrieved using $2 \times 2$ rotational-vibrational transitions of $\mathrm{CO}_{2}$ in the micro-windows from 810.5 to $812.9 \mathrm{~cm}^{-1}$ and 956.0 to $958.2 \mathrm{~cm}^{-1}$. These micro-windows show a sufficient transparency at low altitudes. The spectral transitions used are suited well for a temperature retrieval, since they are sufficiently strong, clearly separable from other signatures, and characterized by different opacities and different temperature dependences. In the temperature retrieval, IFS high-resolution (HRES) operational analyses spectrally truncated at wavenumber 213 and at 137 vertical hybrid levels are used as initial guess and a priori information. The operational ECMWF data were interpolated directly to the GLORIA tangent points. The data are available every $6 \mathrm{~h}$ and are hereafter referred to as "HRES". All retrievals are based on geometric altitude levels. Associated pressures are interpolated from the HRES data. GLORIA's potential temperature is calculated from the retrieved temperature and the HRES pressure field.

Ozone volume mixing ratio is retrieved using several rotational-vibrational transitions in the micro-windows from 780.6 to $781.7 \mathrm{~cm}^{-1}$ and 787.0 to $787.6 \mathrm{~cm}^{-1}$. The ozone initial guess and a priori profile is taken from Remedios et al. (2007). The natural logarithm of water vapour volume mixing ratio is retrieved using a single rotational transition in the microwindow from 795.7 to $796.1 \mathrm{~cm}^{-1}$ and then converted to volume mixing ratio. For initial guess and a priori a vertically constant profile is applied; the value is the logarithm of 10.0 ppmv. In all cases, narrow micro-windows are chosen to minimize spectral interference with pressurebroadened signatures of other gases at lower altitudes. Typical vertical resolutions between 300 and $900 \mathrm{~m}$ are achieved between flight altitude and the lowest tangent point. Finally, the retrieved profiles are combined to 2-D vertical cross sections of the respective target parameters along the flight track.

\subsection{ECMWF IFS forecasts}

The IFS model is a global, hydrostatic, semi-implicit, semiLagrangian NWP model. The IFS cycle 41r1 was operational from 12 May 2015 until 8 March 2016 and utilized a linear grid with a spectral truncation at wavenumber 1279 ( $\left.\mathrm{T}_{\mathrm{L}} 1279\right)$, which corresponds to a horizontal resolution of approximately $16 \mathrm{~km}$. In the vertical, 137 levels (L137) ranged from the model top at a pressure level of $0.01 \mathrm{hPa}$ down to the surface. The vertical resolution in the vicinity of the extra-tropical tropopause is less than $400 \mathrm{~m}$ and increases with decreasing altitude. The IFS cycle 41r1 was replaced by cycle $41 \mathrm{r} 2$ on 8 March 2016. The horizontal resolutions of all the different operational applications using the IFS were upgraded (Hólm et al., 2016). The deterministic high-resolution analyses and forecasts are computed on a cubic octahedral grid with a resolution of approximately $9 \mathrm{~km}$ while the spectral truncation remained at wavenumber 1279 $\left(T_{L} 1279\right)$ (Malardel and Wedi, 2016). A large contribution to the gain in effective resolution of the IFS cycle $41 \mathrm{r} 2$ results from the reduced numerical filtering and the preparation of the physiographic data at the surface.

IFS cycle $41 \mathrm{r} 2$ was running in a pre-operational, experimental suite in January 2016. Here, 1-hourly short-term forecasts of the 00:00 UTC run at 09:00, 10:00, and 11:00 UTC are used. These data were interpolated to a regular $0.25^{\circ} \times$ $0.25^{\circ}$ latitude-longitude grid and will be compared to the GLORIA observations. The IFS data are retrieved as fully resolved fields, containing all 1279 spectral coefficients. Background temperature fields are computed as a moving average within a horizontal window of $3^{\circ}$ in the meridional direction and $4^{\circ}$ in the zonal direction $(\sim 330 \mathrm{~km} \times 330 \mathrm{~km})$. The difference between the fully resolved IFS temperature field (or the GLORIA temperature field) and the IFS background temperature field yields perturbations, which accen- 
tuate mesoscale temperature variations, e.g. due to mountain waves.

Studies using the same IFS cycle are reported in the literature: Ehard et al. (2018) documented the high fidelity of the IFS fields representing the mean stratospheric temperature over Sodankylä, Finland $\left(67.5^{\circ} \mathrm{N}, 26.5^{\circ} \mathrm{E}\right)$, in December 2015 and the gravity activity at this location in the winter of 2015-2016. Dörnbrack et al. (2017) compared the mesoscale structure of mountain-wave-induced polar stratospheric clouds with the simulated temperatures of the IFS and found a remarkable agreement with the space-borne measurements.

\subsection{GLORIA observational filters}

There are two ways to compare the GLORIA data resulting from radiance integrated along extended limb views (Fig. 1) with the numerical IFS fields. First, the time-dependent 3D IFS data are linearly interpolated in space to the GLORIA tangent points which are provided as function of latitude, longitude, altitude, and time. This procedure does not take into account the horizontal smoothing characteristics intrinsic to the GLORIA observations. As a second approach, the observational filters of the GLORIA observations are characterized. In effect, we calculate exemplary 2-D averaging kernels (Ungermann et al., 2011) providing the horizontal and vertical smoothing characteristic along GLORIA's viewing direction (i.e. perpendicular to the flight track). These averaging kernels are then used to smooth the IFS data for comparison. While the first approach is straightforward, the second one requires the following calculation of the 2-D averaging kernels.

According to Rodgers (2000), the averaging kernel matrix $\mathbf{A} \in \mathbb{R}^{n \times n}$ is the product of the gain matrix $\mathbf{G} \in \mathbb{R}^{n \times m}$ and the Jacobi matrix $\mathbf{K} \in \mathbb{R}^{m \times n}$. Thereby $n$ is the number of retrieval grid levels (i.e. altitudes) and $m$ the number of elements of the measurement vector (i.e. spectral grid points within the micro-windows used, for all vertical viewing angles of the measurement). By multiplying $\mathbf{A}$ with the delta between an estimate of the true atmospheric state $\boldsymbol{x}$ (e.g. model data or in situ profile) and the a priori profile $\boldsymbol{x}_{\mathrm{a}}$ used for the retrieval, the atmospheric state projected by the retrieval $\hat{\boldsymbol{x}}$ (i.e. smoothed model or in situ profile) can be calculated as follows (measurement errors neglected):

$\hat{\boldsymbol{x}}=\boldsymbol{x}_{\mathrm{a}}+\mathbf{A}\left(\boldsymbol{x}-\boldsymbol{x}_{\mathrm{a}}\right)$.

This approach is often used for comparing in situ observations or model data of high vertical resolution with a retrieval result with a lower vertical resolution. However, this approach involves a single profile representing the true atmospheric state and assumes homogenous conditions along the viewing direction.

According to Ungermann et al. (2011), a number of profiles representing the true state along the viewing direction can be involved in cases where this condition is not fulfilled.
A modified averaging kernel matrix $\widetilde{\mathbf{A}} \in \mathbb{R}^{n \times(n \cdot o)}$ can be used to replace $\mathbf{A}$ in Eq. (1), with $o$ representing the number of profiles used to sample the variation along the additional dimension along the viewing direction. The 2-D averaging kernel matrix $\widetilde{\mathbf{A}}$ is calculated as the product of $\mathbf{G}$ and a modified Jacobi matrix $\widetilde{\mathbf{K}} \in \mathbb{R}^{m \times(n \cdot o)}$ including the additional horizontal dimension. The individual Jacobi matrix elements are calculated for all elements of the measurement vector and with reference to all discretized retrieval grid levels (vertical domain) and locations along the viewing direction (horizontal domain). We calculate $\widetilde{\mathbf{K}}$ using the $3-\mathrm{D}$ inhomogeneous radiative transfer routine of KOPRA (von Clarmann et al., 2009). The calculations of the elements of $\widetilde{\mathbf{K}}$ are extensive, since the retrieval micro-windows used in the GLORIA highspectral-resolution mode include many spectral grid points. Together with the large number of viewing angles of a single GLORIA data cube (i.e. up to 128 , depending on quality and cloud filtering), large sizes result for $\widetilde{\mathbf{K}}$.

Our aim is to apply the horizontal smoothing procedure for water vapour and temperature and only for two subsections of the flight (i.e. the two passages of the tropopause fold). Therefore, we calculate $\widetilde{\mathbf{K}}$ and $\widetilde{\mathbf{A}}$ for each target parameter only for a single observation characteristic for the respective flight passage. The resulting observational filters $\widetilde{\mathbf{A}}$ for water vapour and temperature are then applied to sample the IFS data of the entire passage. A horizontal discretization of $25 \mathrm{~km}$ is chosen to calculate the elements of $\widetilde{\mathbf{K}}$ along the horizontal dimension, i.e. along the viewing direction. Since the calculation of $\widetilde{\mathbf{K}}$ takes into account the entire light paths of the limb views up to the top of the atmosphere, the discretized elements of $\widetilde{\mathbf{K}}$ are calculated within $1500 \mathrm{~km}$ along the viewing direction. The resulting contributions of $\widetilde{\mathbf{A}}$ far beyond the tangent points are, however, negligible. Therefore, elements of $\widetilde{\mathbf{A}}$ beyond $600 \mathrm{~km}$ are omitted in IFS data sampling.

In the case of temperature, $\widetilde{\mathbf{A}}$ is used together with $\boldsymbol{x}$ (including the $o$ model profiles along the viewing direction) and $\boldsymbol{x}_{\mathrm{a}}$ (including $\boldsymbol{o}$ times the a priori profile) to calculate a single smoothed IFS profile $\hat{\boldsymbol{x}}$ for the comparison with a single corresponding GLORIA profile. In the case of water vapour, $\widetilde{\mathbf{A}}$ is calculated with respect to the natural logarithm of the volume mixing ratio. Since the $3-\mathrm{D}$ inhomogeneous radiative transfer routine of KOPRA provides the Jacobi matrix elements corresponding with volume mixing ratio and not the logarithm, the matrix elements of $\widetilde{\mathbf{K}}$ are post-differentiated with respect to the logarithm of volume mixing ratio. The logarithms of $\boldsymbol{x}$ and $\boldsymbol{x}_{\mathrm{a}}$ are then used in the smoothing procedure of the IFS data.

Figure 2 shows exemplary rows of $\widetilde{\mathbf{A}}$ for water vapour and temperature for the first tropopause fold passage (figuratively: $n \cdot o$ horizontal profiles out of a single row of $\widetilde{\mathbf{A}}$, stacked above each other). The individual panels show how a single-state element of the retrieval result (i.e. target parameter at altitude level indicated at the top of a panel) responds to an atmospheric grid point along the viewing direc- 

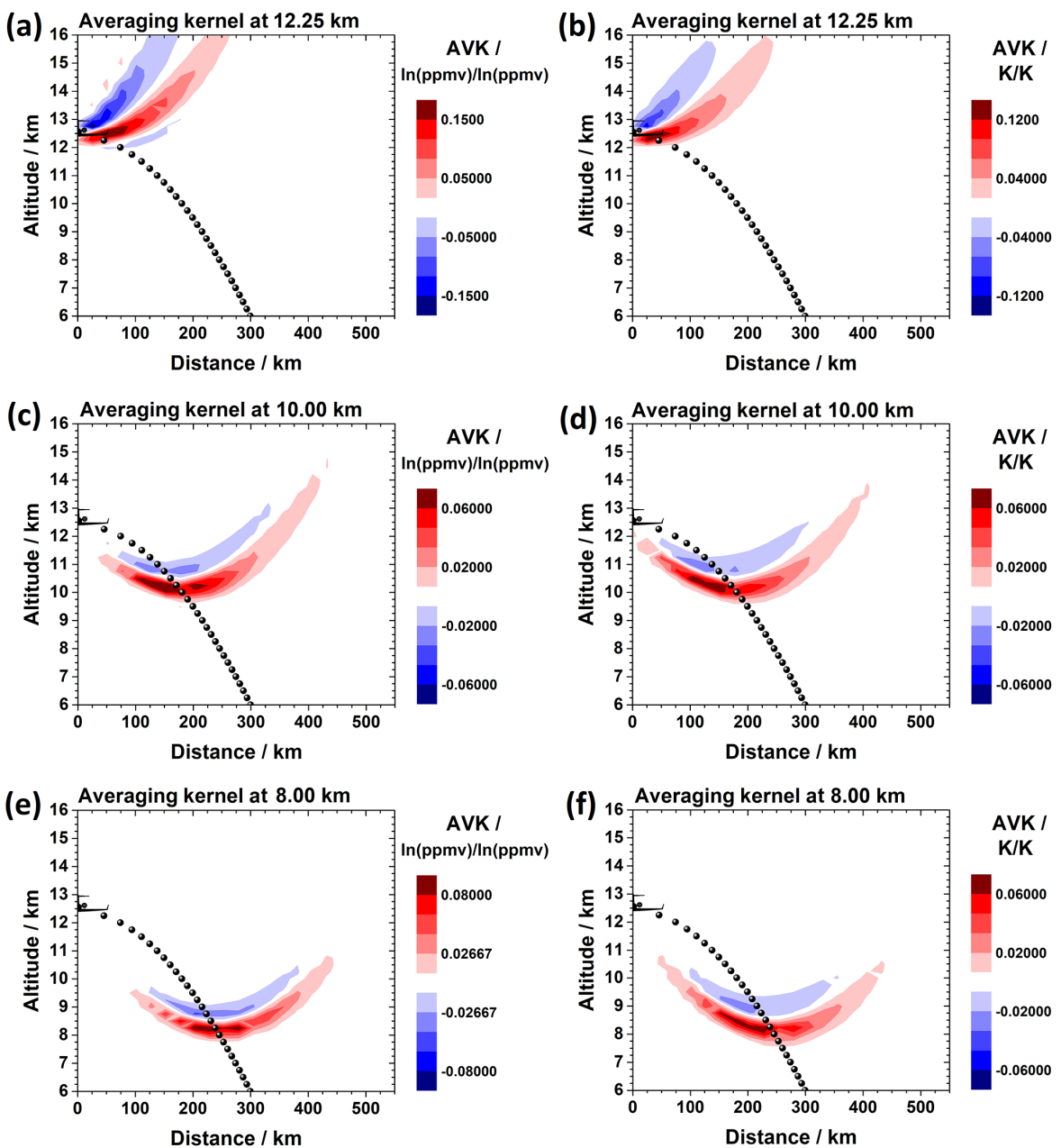

Figure 2. GLORIA observational filters including the horizontal domain along the line of sight. The plots show rows of the 2-D averaging kernels $\widetilde{\mathbf{A}}$ for the logarithm of water vapour $(\mathbf{a}, \mathbf{c}, \mathbf{e})$ and temperature $(\mathbf{b}, \mathbf{d}, \mathbf{f})$ corresponding with the retrieval grid levels indicated at the top of the panels. Black dots in all panels: retrieval grid tangent points of the GLORIA retrieval.

tion (characterized by geometric altitude and horizontal distance) in the true state (Ungermann, 2011; Ungermann et al., 2011). Thereby, "constructive" contributions (in red) correspond with atmospheric grid points where a higher (lower) value in the true state results in a higher (lower) value in the retrieval result. However, "destructive" contributions (in blue) correspond with atmospheric grid points where a higher (lower) value in the true state, counter-intuitively, results in a lower (higher) value in the retrieval result. In this manner, the response of the retrieval and its weighting functions in the vertical and horizontal domain along the viewing direction are characterized.

In Fig. 2, $\widetilde{\mathbf{A}}$ is calculated for the measurement at a geolocation at $725 \mathrm{~km}$ along flight path (compare Fig. 8). Thereby, the latitude of the uppermost tangent points is $\sim 42.46^{\circ} \mathrm{N}$ (compare Fig. 6). For the second passage (not shown), $\widetilde{\mathbf{A}}$ was calculated for the measurement at a geolocation at $2852 \mathrm{~km}$ along flight path, with the uppermost tangent points at $\sim$ $42.33^{\circ} \mathrm{N}$. In the case of water vapour (Fig. 2a, c, and e), the plots show the response of the logarithm of water vapour at the indicated retrieval grid level to variations in the logarithm of water vapour in the true state (i.e. interpolated IFS data) along the viewing direction. In the case of temperature, the response of retrieved temperature at the indicated level to variations of temperature in the true state along the viewing direction is shown in the same manner (Fig. 2b, d, and f).

Figure $2 \mathrm{a}$ and $\mathrm{b}$ show the situation at a retrieval grid level of $12.25 \mathrm{~km}$, which approximately coincides with the flight altitude $(\sim 12.40 \mathrm{~km})$ during the measurement. In the case of the logarithm of water vapour (Fig. 2a), the retrieval result is dominated by constructive contributions within an arched lobe peaking $\sim 50-100 \mathrm{~km}$ away from the observer. Further significant constructive contributions originate from locations closer to the observer position, and also a long tailing towards higher altitudes further away is noted. Another significant destructive lobe is found above the dominating 
constructive lobe. Here, the presence of more water vapour in the true state diminishes the retrieval result at the indicated level. For temperature (Fig. 2b), the result is similar to the logarithm of water vapour. Here, the constructive lobe peaks slightly closer to the observer position at a distance of $\sim 25$ $75 \mathrm{~km}$.

The response at the retrieval grid level of $10 \mathrm{~km}$ is shown in Fig. 2c and d. For both the logarithm of water vapour and temperature, the arched constructive lobes are centred approximately at the corresponding retrieval grid tangent point. However, the main maxima are shifted by about $50 \mathrm{~km}$ towards the observer and a few hundreds of metres to higher altitudes. Behind the tangent point, the constructive lobes extend further to higher altitudes in both cases. Furthermore, a weak destructive lobe is found on top of the dominating constructive lobe in both cases. Overall, the bulk response is found in a region roughly within about $\pm 100 \mathrm{~km}$ around the tangent point (i.e. shifted slightly to the observer in the case of temperature).

The responses at $8 \mathrm{~km}$ shown in Fig. 2e and $\mathrm{f}$ show a similar pattern. In the case of the logarithm of water vapour (Fig. 2e), again a constructive main lobe and a weak destructive lobe are found. Their maxima are aligned more symmetrically around the corresponding tangent point when compared to Fig. 2c and d. In the case of temperature (Fig. 2f), both the constructive main lobe and the weaker destructive lobe develop to be stronger at the observer-facing side of the tangent point, with the extrema shifted by $\sim 50 \mathrm{~km}$ to the observer. Again, the bulk response originates from a region within about $\pm 100 \mathrm{~km}$ around the tangent point (i.e. in the case of temperature shifted slightly to the observer).

Overall, the results in Fig. 2 show that the retrieval results at certain altitudes are affected significantly by regions around and above the tangent points as a consequence of the viewing geometry and the retrieval algorithm. This is of particular importance for comparisons with highly resolved model data including local fine structures (see Fig. 6b). In the following, we use exemplary observational filters $\widetilde{\mathbf{A}}$ both for water vapour and temperature, calculated for the respective tropopause fold passages for detailed comparisons with the IFS.

\subsection{In situ observations}

The temperature data retrieved from the GLORIA observations are compared with static air temperature at flight altitude provided by HALO's Basic Halo Measurement and Sensor System (BAHAMAS, Krautstrunk and Giez, 2012). The static air temperature data are characterized by a total uncertainty of $0.5 \mathrm{~K}$ and are available with a temporal resolution of $1 \mathrm{~s}$. Furthermore, vertical profiles of temperature and water vapour retrieved from the GLORIA measurements are compared with the radiosonde profile of the 12:00 Z (11:00 UTC) launch from LIRE Pratica Di Mare (station number 16245) on the flight day (available at http:

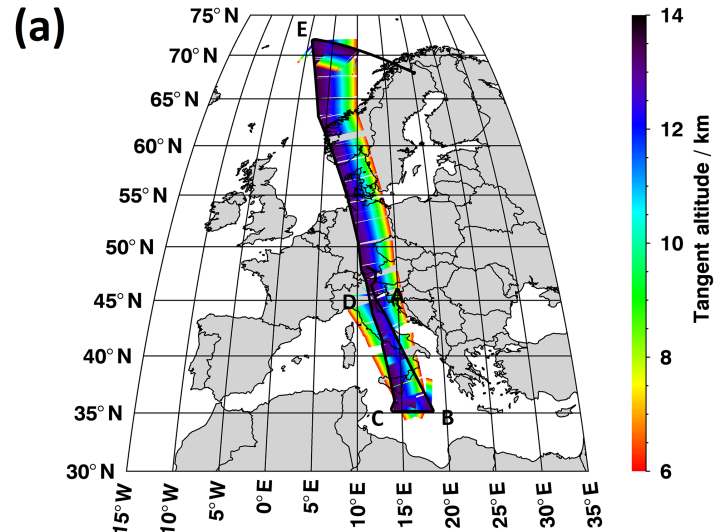

(b)

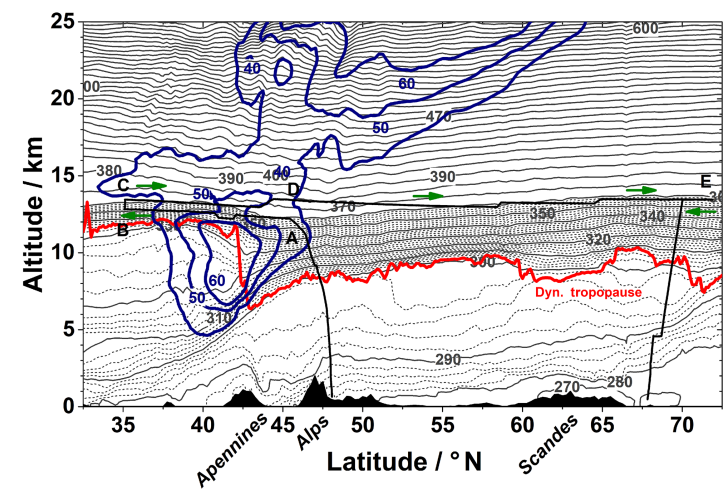

Figure 3. Horizontal and vertical profiles of the HALO flight PGS06 on 12 January 2016: (a) flight legs (black line) and tangent points of GLORIA observations, colour-coded with tangent altitude in kilometres; (b) flight track (black line) and topography (black). Green arrows indicate flight direction. Contours: Horizontal wind ( $\mathrm{m} \mathrm{s}^{-1}$, blue lines) and potential temperature $\Theta(\mathrm{K}, \Delta \Theta=10 \mathrm{~K}$, solid lines and $\Delta \Theta=2 \mathrm{~K}$, dashed lines up to $\Theta=360 \mathrm{~K}$ ) at $13^{\circ} \mathrm{E}$ from ECMWF IFS, valid at 10:00 UTC. Waypoints A, B, C, D, and $\mathrm{E}$ are mentioned in the text.

//weather.uwyo.edu/upperair/sounding.html, last access: 10 October 2018). Typical radiosonde measurement uncertainties are 0.4 to $1 \mathrm{~K}$ for temperature, around $24 \%$ for water vapour below $-50{ }^{\circ} \mathrm{C}$, and between $5 \%$ and $14 \%$ at higher temperatures (Nash, 2015). However, low stratospheric water vapour mixing ratios are not resolved by the radiosonde data.

\section{Meteorological conditions during research flight PGS06}

Research flight PGS06 was designated as a survey and ferry flight from Oberpfaffenhofen, Germany $\left(48^{\circ} \mathrm{N}, 11^{\circ} \mathrm{E}\right)$, via Malta $\left(36^{\circ} \mathrm{N}, 14^{\circ} \mathrm{E}\right)$, and, eventually, to Kiruna, Sweden $\left(68^{\circ} \mathrm{N}, 20^{\circ} \mathrm{E}\right)$. HALO took off at 07:56 UTC and landed at 16:49 UTC on 12 January 2016. The total flight track along with GLORIA's tangent points is shown in Fig. 3a. 
In this paper, we focus on the two legs $\mathrm{A}-\mathrm{B}$ and $\mathrm{C}-\mathrm{D}$. On the southbound leg A-B, atmospheric observations by GLORIA pointed westwards and started above northern Italy at $\sim$ 08:25 UTC, reaching waypoint B at 09:52 UTC. On the northbound transect C-D, GLORIA pointed east towards the preceding leg $\mathrm{A}-\mathrm{B}$ and took observations from 10:26 to 11:54 UTC.

Figure $3 \mathrm{~b}$ displays the vertical profile of the flight track projected onto $13^{\circ} \mathrm{E}$ along the wide-ranging latitude band flown during PGS06. To set this research flight into a meteorological context, lines of constant potential temperature $\Theta$ (isentropes), the height of the dynamical tropopause (2 PVU line), and selected contour lines of constant wind are added from the IFS data valid at 12 January 2016, 10:00 UTC. The atmospheric flow consists of two dominating jets. Between 50 and $60^{\circ} \mathrm{N}$, the horizontal wind of the stratospheric polar night jet (PNJ) attains more than $120 \mathrm{~m} \mathrm{~s}^{-1}$ at about $40 \mathrm{~km}$ altitude (not shown). At its lower and equatorward edge, the PNJ merges with the PFJ which is south of the Alps at about $42^{\circ} \mathrm{N}$ (Fig. 3b). Here, horizontal winds maximize with about $70 \mathrm{~m} \mathrm{~s}^{-1}$ at $10 \mathrm{~km}$ altitude. These jets roughly mark the edge of the Arctic polar vortex. At the jet axis, there is a sharp jump in the height of the dynamical tropopause. On isentropic surfaces, say at $320 \mathrm{~K}$, this discontinuity in potential vorticity (PV) between the cyclonic (northward) and anticyclonic (southward) shear side restricts the transitions of air masses between the stratosphere (north) and troposphere (south). Generally, intrusions of stratospheric air into the troposphere proceed in stably stratified layers with high PV values (Shapiro et al., 1980). As the tropopause wraps or folds around the jet core, such patterns are usually called tropopause folds. Underneath the core of the PFJ, the strongly tilted isentropic surfaces mark the associated baroclinic frontal zone. Except for the appearance of stratospheric gravity waves above and poleward of the core of PFJ, the cross section as presented in Fig. $3 \mathrm{~b}$ resembles the schematic sketch by Shapiro et al. (1987, Fig. 17) of the locations and altitudes of frontal systems. Even the Arctic front near $70^{\circ} \mathrm{N}$ is visible in Fig. 3b.

At the beginning of the southbound leg A-B, HALO climbed up to the lowermost stratosphere and reached the $\Theta \approx 360 \mathrm{~K}$ isentropic surface at the cyclonic side of PFJ. After overflying the tropopause fold as indicated by the convoluted 2 PVU contour line underneath the flight level, HALO intersected the $350 \mathrm{~K}$ isentropic surface at the anticyclonic side of the PFJ. During the northbound leg C-D, HALO reached the $360 \mathrm{~K}$ isentropic surface again and climbed up to higher altitudes. Isentropic levels of $\Theta \approx 370$ and $380 \mathrm{~K}$ were reached further north at 44 and $47^{\circ} \mathrm{N}$, respectively, as a consequence of the lower troposphere. During the long transect toward waypoint E in the Arctic, HALO further climbed to higher altitudes and at the same time entered the $360 \mathrm{~K}$ isentrope again due to the overall meridional gradient of the isentropes.
As outlined by Bramberger et al. (2018, their Fig. 3), the synoptic situation was characterized by a large-scale upperlevel trough above northern Italy and mid-Europe leading to a remarkable north-south gradient of the height of the dynamical tropopause along the flight track (Fig. 3b). Here, Fig. 4 juxtaposes horizontal cross sections of water vapour and horizontal wind at the $320 \mathrm{hPa}$ pressure surface $(\approx 9 \mathrm{~km}$ altitude) of the IFS forecasts valid at 09:00 and 11:00 UTC, respectively. As expected, there is a large meridional gradient in water vapour with lower values toward the north and higher values in the south (Fig. 4a, b). At the cyclonic shear side of the PFJ, the lower water vapour mixing ratios appear to be more textured, most probably due to frontal convection and the interaction of the weather system with the Alps. South of the Alps and north of about $43^{\circ} \mathrm{N}$, a zonally elongated, nearly homogeneous band of very low water vapour values of less than 10 ppmv (deep blue colours in Fig. 4a, b) indicates the dry intrusion of stratospheric air associated with the tropopause fold. The PFJ and the associated tropopause fold extended zonally between 44 and $42^{\circ} \mathrm{N}$ from southern France to Italy (Fig. 4c, d). Maximum horizontal winds of the PFJ exceeded $70 \mathrm{~m} \mathrm{~s}^{-1}$ at this level and are located south of this dry intrusion. During the $3.5 \mathrm{~h}$ when research flight PGS06 travelled between waypoints A and $\mathrm{D}$, the whole structure of the wind and water vapour fields changed only marginally as the meteorological system propagated slowly south-eastward. Therefore, we can assume that GLORIA sampled air masses in the same meteorological situation on the south- and northbound legs, respectively. Possible differences in the observations must be associated with local atmospheric processes along and underneath the respective observational paths. Additionally, as is obvious from the orientations of the individual flight legs, the viewing directions are not parallel in both legs and cut the tropopause fold differently, compare Figs. 3a and 4.

Figure 5 displays the vertical wind and the temperature perturbations at the $180 \mathrm{hPa}$ pressure surface $(\approx 13 \mathrm{~km}$ altitude) which corresponds approximately to HALO's flight level on 12 January 2016. The strong westerly low-level flow excited mountain waves over the Pyrenees, the French Alps, Corsica-Sardinia, and the Apennines (Bramberger et al., 2018). The corresponding up- and downdrafts remained nearly stationary in the period considered but their amplitude attenuated slightly in time (Fig. 5a, b). Similar but considerably broader patterns are also identified in the mountainwave-induced temperature perturbations (Fig. 5c, d). As in the case of vertical wind, the major structures remained mostly stationary, while amplitudes and patterns changed on smaller scales. The amplitude of the temperature perturbation faded out somewhat at 11:00 UTC (Fig. 5d). A positive temperature perturbation is enframed by HALO's southand northbound legs between 42 and $43^{\circ} \mathrm{N}$. This temperature anomaly is located above the core of the jet stream (cf. Fig. 4c) and is well covered by the GLORIA observations along the southbound flight leg A-B. As explained in 
(a)

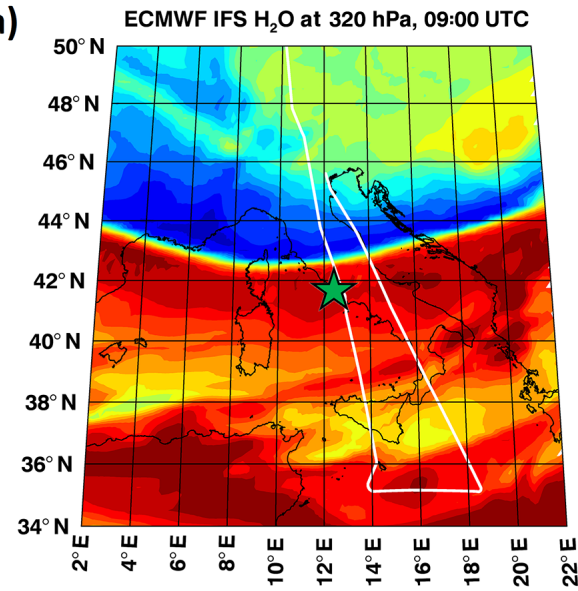

(c)

ECMWF IFS horizontal wind at $320 \mathrm{hPa}, 09: 00 \mathrm{UTC}$

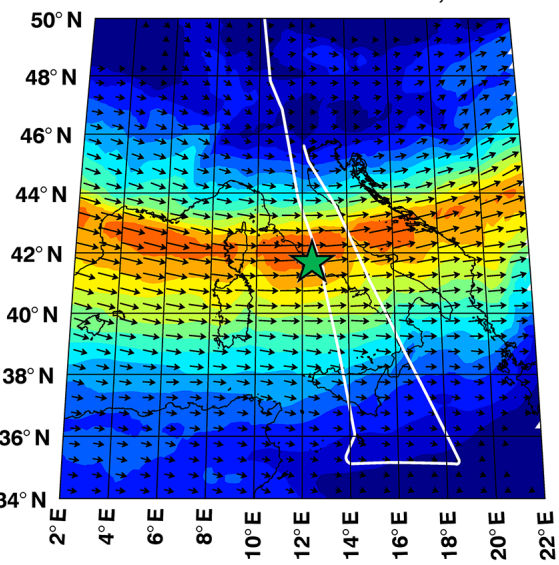

(b)
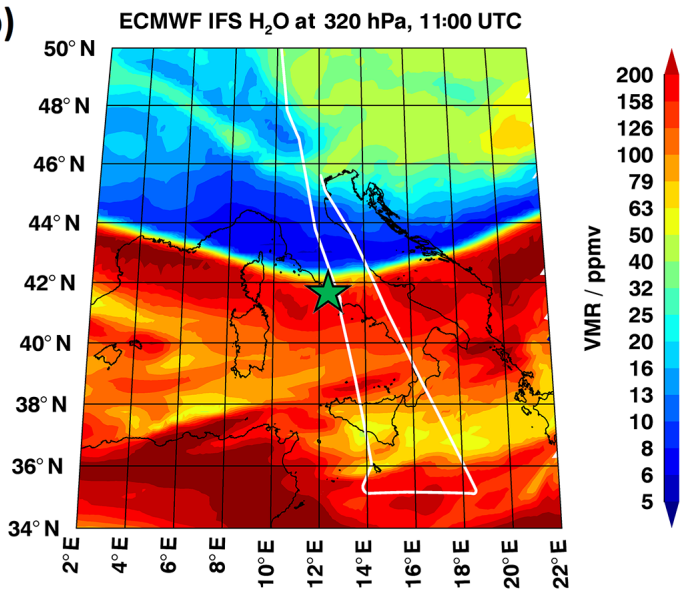

(d)

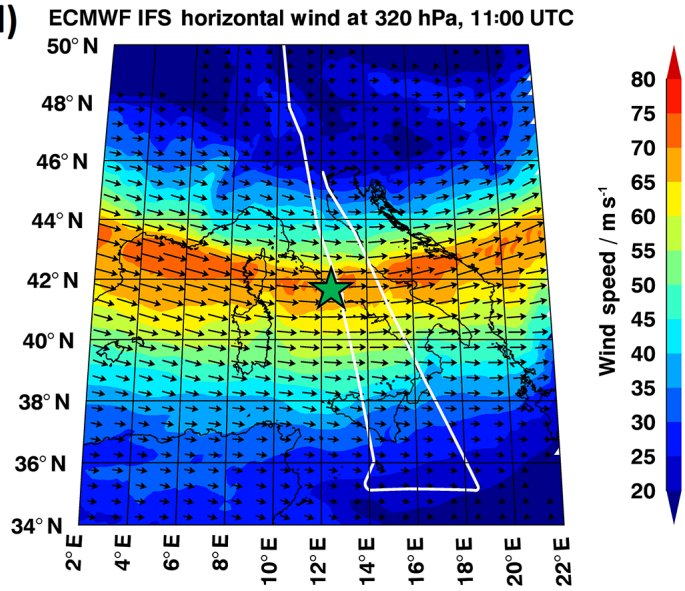

Figure 4. Horizontal section of water vapour mixing ratio (a, b) and horizontal wind (c, d) at the $320 \mathrm{hPa}$ pressure surface at 09:00 UTC (a, c) and 11:00 UTC $(\mathbf{b}, \mathbf{d})$ on 12 January 2016. White lines: HALO flight track between $\sim 08: 25$ and 12:30 UTC. Green star in all panels: LIRE Pratica De Mare radiosonde launch site.

detail by Bramberger et al. (2018), mountain-wave-induced flow perturbations as represented by the local down- and updrafts above the Apennines are responsible for the observed changes in ambient temperature along the southbound flight leg.

Figure 6 presents longitude-altitude sections of water vapour, horizontal and vertical winds, and temperature perturbations of the IFS data at $42.46^{\circ} \mathrm{N}$ and valid at 09:00 UTC when the mountain wave amplitudes were maximum in the IFS (Fig. 5c). Also shown is a projection of GLORIA's tangent points (data cube with uppermost tangent point coinciding with the indicated latitude). As mentioned above, GLORIA's viewing direction was not exactly east-west but approximately towards the south-west during the southbound leg. The water vapour distribution reveals the existence of a dry stratospheric intrusion associated with the tropopause fold at about $400 \mathrm{hPa}$ and west of about $12^{\circ} \mathrm{E}$. At higher levels, the dry stratospheric air stretched across the whole Italian peninsula (Fig. 6a). Thus, GLORIA viewed along a zonally rather homogeneous water vapour distribution at this latitude above $280 \mathrm{hPa}$. As GLORIA viewed nearly perpendicular to the strong north-south water vapour gradient (see Fig. 4), the successive measurements along the flight track sampled the meridional structure densely and, eventually, resolved the meridional variation inside the tropopause fold very sharply. At the same time, the blurred horizontal focus in the viewing direction was nearly directed in the zonal direction into a much smaller variability, leading to the propitious viewing geometry for sampling the tropopause fold.

Figure $6 \mathrm{~b}$ documents the more complicated situation regarding the temperature perturbations due to the mountain waves along the GLORIA viewing direction. Here, HALO is located in a lobe of colder temperatures stretching from below the aircraft to above $100 \mathrm{hPa}$. Along the uppermost tangent points, the temperature perturbations vary remarkably in the zonal direction within several tens of kilometres. The impact of the mountain waves can be also seen by undulations of the PFJ (Fig. 6c) as well as of the water vapour distribution above the Apennines (Fig. 6a), especially, at stratospheric levels higher than $200 \mathrm{hPa}$. Furthermore, the 

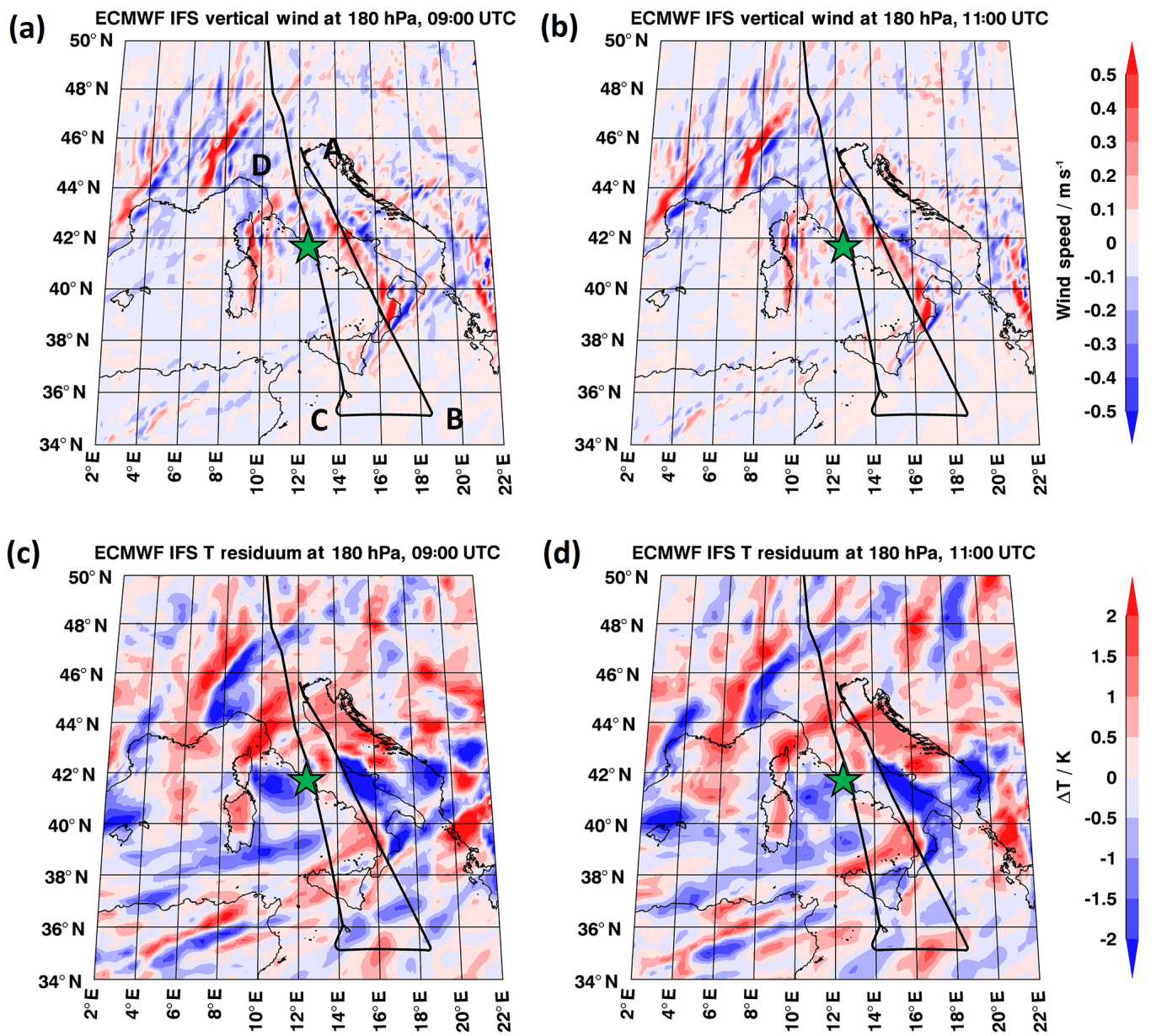

Figure 5. Mountain wave activity on 12 January 2016. Vertical wind $\left(\mathrm{m} \mathrm{s}^{-1}\right.$, colour shading) at $180 \mathrm{hPa}$ forecasted by the IFS at 09:00 and 11:00 UTC (a, b). Temperature perturbations (K, colour shading) at 180 hPa forecasted by the IFS at 09:00 and 11:00 UTC (c, d). Black lines: HALO flight track between $\sim 08: 25$ and 12:30 UTC. Green star in all panels: LIRE Pratica De Mare radiosonde launch site.

IFS vertical wind is shown in Fig. 6d. The strongest updraft of about $0.8 \mathrm{~m} \mathrm{~s}^{-1}$ is found around $14^{\circ} \mathrm{E}$ just below the aircraft (Fig. 6d). The vertical wind is in quadrature with the temperature anomalies: cold anomalies are associated with phase fronts of the largest upward displacement and follow phase fronts of upward winds (adiabatic cooling) and warm anomalies are associated with the largest downward displacement after downward winds (adiabatic heating). The IFS data as presented in Fig. 6 show that the temperature, wind, and water vapour fields were influenced by vertically propagating mountain waves which interacted with the tropopause fold above the Apennines. According to the IFS data, the GLORIA viewing direction was aligned across horizontal temperature contrasts approaching $\pm 2 \mathrm{~K}$ within a few tens of kilometres in the upper part of the observations. Therefore, the comparison of the horizontally blurred GLORIA data (along the viewing direction) with the model data sampled sharply at the tangent points can be strongly influenced by the observational filter. Further down at altitudes below the $220 \mathrm{hPa}$ level, the IFS data show a more homogenous temperature distribution along the GLORIA tangent points.

\section{Comparison of GLORIA and in situ data}

Figure 7 displays both a comparison of the GLORIA data at flight level with the BAHAMAS in situ temperature data between waypoints $\mathrm{A}$ and $\mathrm{D}$ as well as the comparison of the retrieved vertical temperature and water vapour profiles with the LIRE 12:00Z (11:00 UTC) radiosonde sounding (for launch site see star marked in Figs. 4 and 5). Note, no suitable flight level in situ water vapour data are available for PGS06.

\subsection{Flight level data}

Figure 7a shows GLORIA water vapour (red) and the pressure at flight altitude (black). The grey lines mark the constant $10 \mathrm{ppmv}$ values of the initial guess and a priori pro- 

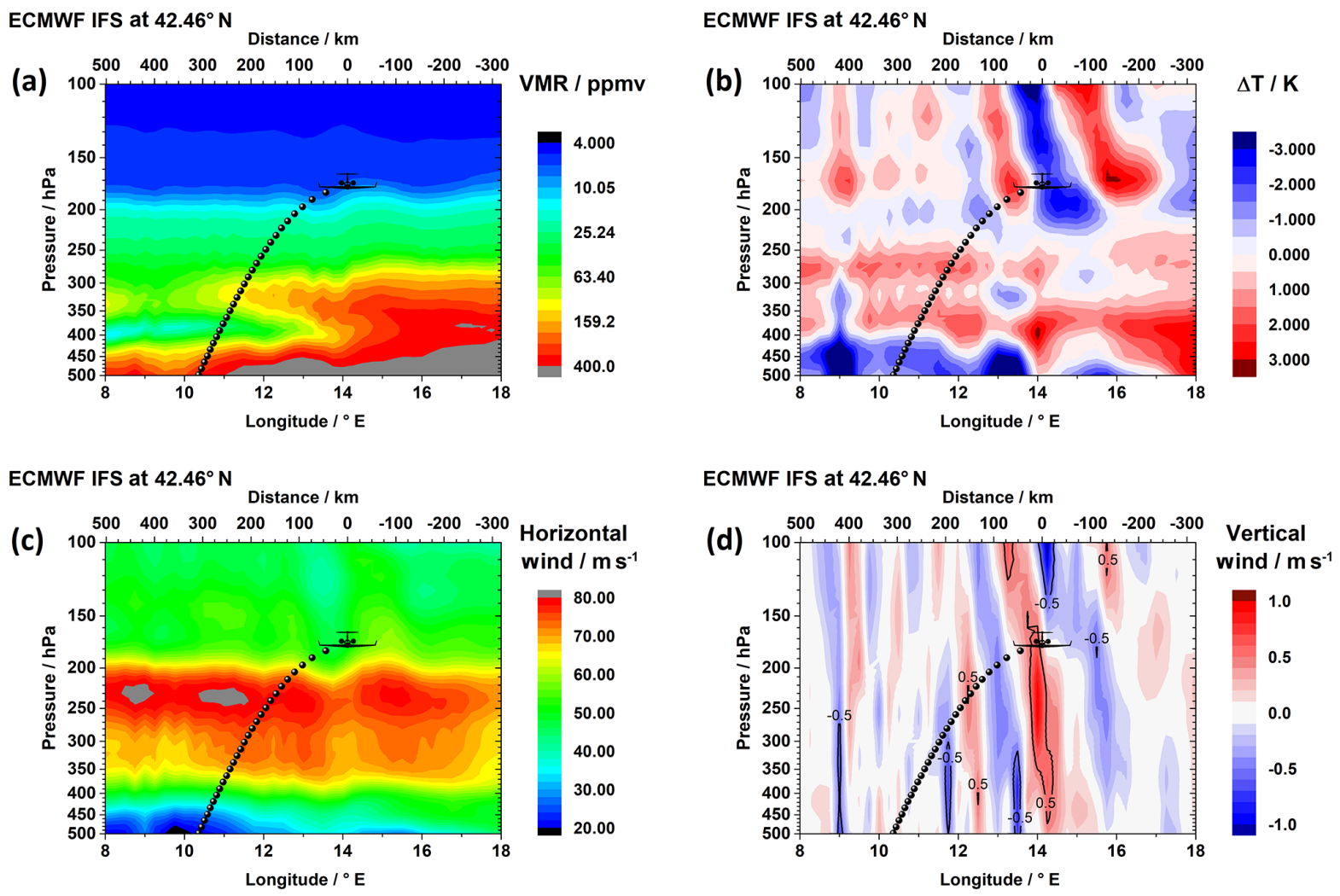

Figure 6. Vertical cross sections of IFS water vapour (a), temperature perturbations (b), horizontal wind (c), and vertical wind (d). Black dots in both panels: projection of GLORIA tangent points (of data cube with uppermost tangent points coinciding with indicated latitude). Note that the GLORIA viewing direction was aligned not exactly in the zonal direction, but slightly tilted to the south-west (see Fig. 3a).

file used for GLORIA's water vapour retrieval. Regions highlighted in yellow indicate where the GLORIA tangent points passed the radiosonde launch site $\pm 50 \mathrm{~km}$. Right at waypoint A, GLORIA measured dry stratospheric air of about 3-5 ppmv at the cyclonic shear side of the PFJ. Further southward, water vapour mixing ratios increased gradually as HALO approached the tropopause layer. Water vapour varied at upper tropospheric mixing ratios between $>6$ and 22 ppmv up to waypoint B. Thereby, the strongly oscillating signature of the observed water vapour might be related to the wave-induced up- and downdrafts along GLORIA's viewing paths (see Fig. 5a, b). At a distance of $\sim 800 \mathrm{~km}$, HALO had to lower the flight level by $\sim 10 \mathrm{hPa}$ temporarily for safety reasons (see dip in pressure in Fig. 7a). Here, an unexpected feature is observed. While the water vapour mixing ratio of $\sim 9$ ppmv before the descent would be assumed to increase, the opposite is found: the water vapour mixing ratios drop back to stratospheric values of about $5 \mathrm{ppmv}$ at minimum and rise again to $\sim 9$ ppmv as HALO climbed back to $180 \mathrm{hPa}$ (FL410). Bramberger et al. (2018) explain this flight sequence in detail and GLORIA's water vapour observations can be interpreted by the abruptly changing sign of the vertical wind induced by the mountain waves along HALO's flight track. Thus, GLORIA measured descending dry strato- spheric air related to the mountain waves at this location. The subsequent ascent of HALO to FL430 $(\sim 160 \mathrm{hPa})$ after waypoint $\mathrm{B}$ brought the observed water vapour mixing ratios back to stratospheric levels. The amplitude of the water vapour oscillations along the northbound leg are much smaller since HALO was flying entirely inside stratospheric air masses.

Figure $7 \mathrm{~b}$ shows the comparison of GLORIA temperature data (red) with the BAHAMAS temperature data (blue) along the flight track. The ECMWF HRES temperature data used as initial guess and a priori information for the GLORIA temperature retrieval are superimposed as a grey line. The smooth HRES profile follows the BAHAMAS data, roughly indicating that the HRES data represent the largescale meridional temperature variations very well. Likewise, GLORIA's retrieval results follow the in situ observations very closely. However, the GLORIA measurements reveal stronger temperature variations and more scattering than the HRES profile. In some flight sections (e.g. 900 to $1400 \mathrm{~km}$ and 3300 to $3700 \mathrm{~km}$ ), the GLORIA results clearly resemble the BAHAMAS data more closely than the much smoother HRES data.

However, there are moderate deviations between the GLORIA and the BAHAMAS data which can be explained by 
(a)

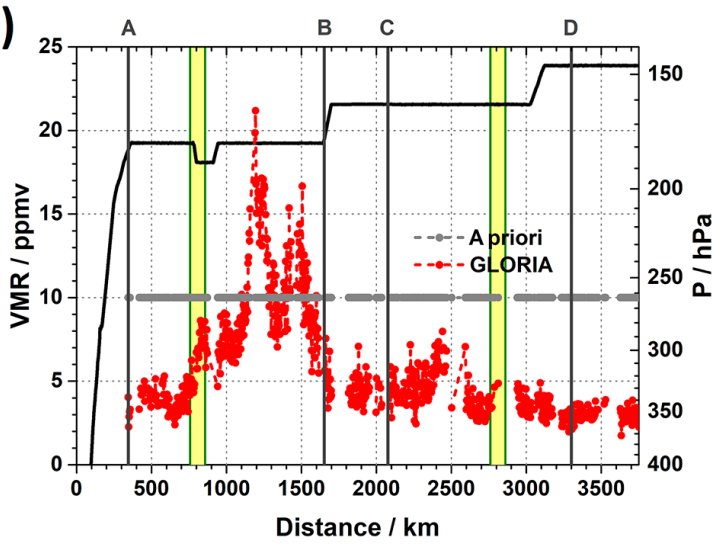

(c)

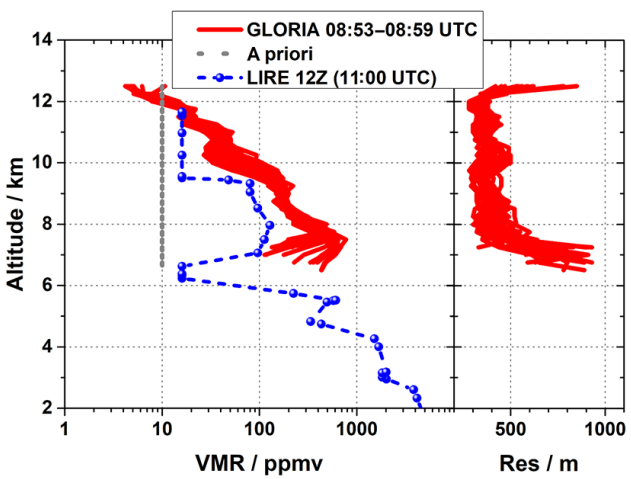

(e)

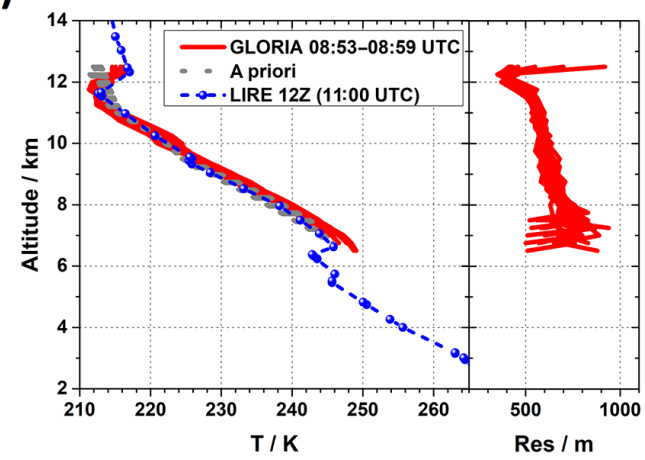

(b)

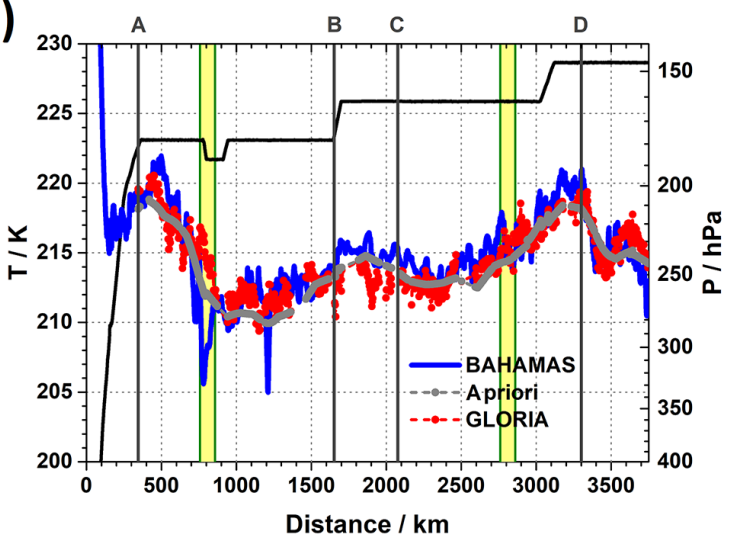

(d)

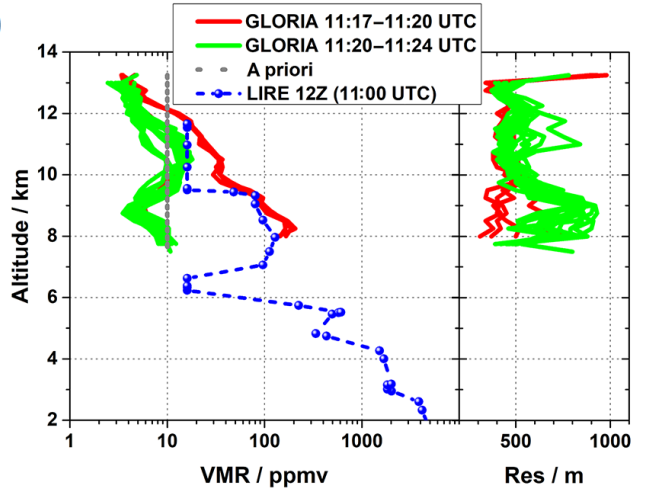

(f)

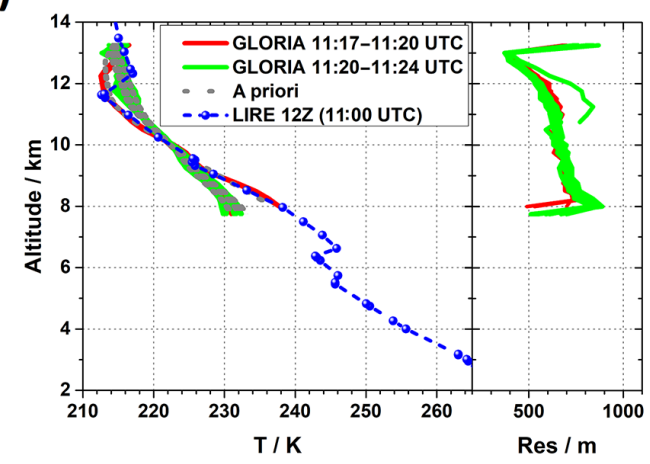

Figure 7. Comparison of GLORIA data with in situ data along flight track and radiosonde data. (a) GLORIA water vapour and initial guess and a priori data along flight track. (b) GLORIA temperature data, HRES initial guess and a priori data, and BAHAMAS in situ data along flight track. Flight altitude in (a) and (b) is shown in black and refers to the right $y$ axis. Windows highlighted in yellow correspond with the passages of the radiosonde launch site. (c, d) GLORIA water vapour profiles and constant 10 ppmv initial guess and a priori profiles during first and second passage of the radiosonde launch site together with the radiosonde profile. (e, f) GLORIA temperature profiles and HRES initial guess and a priori profiles during first and second passage of the radiosonde launch site together with the radiosonde profile.

the different regions sampled, since the horizontal focus of the GLORIA observations at flight altitude is located about $50 \mathrm{~km}$ away from the carrier. For example, the negative offset of GLORIA temperature by 1-2 K compared to BAHAMAS directly south of waypoint A could be produced by zonal temperature gradients induced by the mountain waves whose phases are nearly aligned parallel to the flight track; see Fig. 5c and d. Moreover, a strong anticorrelation is seen between the GLORIA and BAHAMAS data during the first crossing of the radiosonde launch site. There, the BAHAMAS temperature drops by more than $5 \mathrm{~K}$ within several tens of kilometres, while the GLORIA temperatures rise by $2-3 \mathrm{~K}$ at the same time. This anticorrelation can be explained by the mentioned phase orientation of the mountain-wave-induced temperature perturbations. While HALO streaked along a strong local temperature minimum, the GLORIA temperatures observed remotely 
were dominated by a wave-induced, local temperature maximum located west of the flight track.

\subsection{Radiosonde sounding}

Figure 7c-f compare the GLORIA profiles with the LIRE radiosonde sounding at 11:00 UTC during the first and second HALO passages of the launch site. All GLORIA profiles from the two segments marked in yellow in Fig. 7a and b are considered for the comparison. In the case of water vapour (Fig. 7c and d), the constant 10 ppmv initial guess and a priori profile is also shown. As background reference for temperature, the initial guess and a priori HRES profiles are added again (Fig. 7e and f). While the geographical match of GLORIA tangent points covering the launch site was better during the first passage (Fig. 7c, e), the time period of the second passage suits the sounding better (Fig. 7d, f; GLORIA data measured shortly after 11:00 UTC). However, during the second passage, GLORIA was pointing away from the launch site, and a v-shaped gap is found in the tangent point distribution due to a slight azimuth turn of HALO and a data gap. The vertical resolution of the GLORIA profiles as derived from the traces of the usual 1-D averaging kernels of the profiles are shown on the right-hand-side panels of Fig. 7c-f. They amount to 300 to $600 \mathrm{~m}$ below flight altitude. Further down, the vertical resolution deteriorates towards about $900 \mathrm{~m}$. Above the flight level, the vertical resolution decreases rapidly due to the sampling characteristics of the airborne limb observations.

Below the flight level and above $11 \mathrm{~km}$ altitude, both the GLORIA and radiosonde data show typical dry stratospheric water vapour mixing ratios, which increased markedly to tropospheric values below $10 \mathrm{~km}$ (Fig. 7c, d) as HALO was located south of the tropopause break; see Fig. 3b. The sounding indicates $\mathrm{H}_{2} \mathrm{O}$ mixing ratios of around $\sim 100 \mathrm{ppmv}$ down to $7 \mathrm{~km}$ whereas the GLORIA profiles measure larger values up to 800 ppmv. During the first passage, all the GLORIA profiles show qualitatively the same altitude dependence (Fig. 7c). Both GLORIA and the sounding detected the strong decrease in water vapour associated with the stratospheric intrusion at about $6 \mathrm{~km}$ altitude. During the second passage, however, two different GLORIA profiles are found (Fig. 7d). While one branch (red) follows the radiosonde data closely, the second branch (green) remains at very low stratospheric water vapour levels at all altitudes. The absence of a smooth transition between the two branches can be explained by a data gap and slight azimuth turn of HALO. As a consequence of both, GLORIA's viewing direction changed, and horizontally separated air masses with different humidity were sampled. Unlike the GLORIA measurements, the sounding data indicate another dry stratospheric intrusion as a water vapour minimum at around $5 \mathrm{~km}$ altitude.

The comparison of the GLORIA temperature profiles with the radiosonde data are shown in Fig. 7e and $\mathrm{f}$. The temperature sounding shows a vertical profile where the tropopause is characterized by a pronounced inversion at about $12 \mathrm{~km}$, the tropopause inversion layer (TIL). GLORIA observations reproduce the TIL as well as the upper tropospheric lapse rate very well during the first passage on the southbound leg. During the second passage, as for the water vapour profiles, two profile branches are visible in the GLORIA data: one set of profiles (red) follows closely the sounding below $12 \mathrm{~km}$ altitude and shows a sharp TIL. The other one (green) associated with the dry air masses exhibits a lower lapse rate and temperatures lower by $10 \mathrm{~K}$ at $8 \mathrm{~km}$. This suggests that dry descending stratospheric air within the tropopause fold is responsible for this finding. Furthermore, at the height of the $\mathrm{H}_{2} \mathrm{O}$ minimum, the radiosonde sounding detected shallow layers of stably stratified air (Fig. 7e, f). The coincidence of local inversions with low water vapour values is in agreement with the conceptual picture of stratospheric intrusions into the troposphere, as mentioned in the Introduction. Unfortunately, no GLORIA data exist at these lower levels.

\section{Results}

\subsection{Overview}

Figure $8 \mathrm{a}, \mathrm{b}$, and e overview the water vapour, temperature, and ozone distributions observed by GLORIA between waypoints $\mathrm{A}$ and $\mathrm{D}$. The tropopause fold can be identified by extruding dry and ozone-rich air extending down and southward from the stratosphere into the troposphere. The tonguelike extensions of stratospheric air are located between 300 and $800 \mathrm{~km}$ during the southbound as well as between 2700 and $3300 \mathrm{~km}$ during the northbound leg (Fig. 8a, e). Within the tropopause fold, narrow bands of dry filaments with enhanced ozone values suggest advective processes as the main driver of their formation. Both at the upper north and lower south edges of the tropopause fold, gentle horizontal $\mathrm{H}_{2} \mathrm{O}$ gradients point to diffusive processes levelling the troposphere-stratosphere contrast out. Temperature observations across the tropopause fold confirm the expected reversal of the meridional temperature gradient from the lower troposphere to the upper troposphere, which is responsible for closing the jet stream in the lower stratosphere (Fig. 8b). South of the tropopause fold at the anticyclonic side of the PFJ, GLORIA observed a rather gradual, diffusive transition of high tropospheric to very low stratospheric $\mathrm{H}_{2} \mathrm{O}$ values between 300 and $180 \mathrm{hPa}$. At certain places, high $\mathrm{H}_{2} \mathrm{O}$ values seem to be injected into stratospheric altitudes. Interestingly, the low ozone values in this part of the flight suggest that the air is mainly transported upwards; there are only a few segments where ozone mixing ratios are enhanced, indicating mixing processes between the stratosphere and troposphere. We refer to this layer as the extratropical transition layer (ExTL), Gettelmann et al. (2011), as it marks the crossover from tropospheric to stratospheric air. Moreover, the presence of rather cold stratospheric spots with 

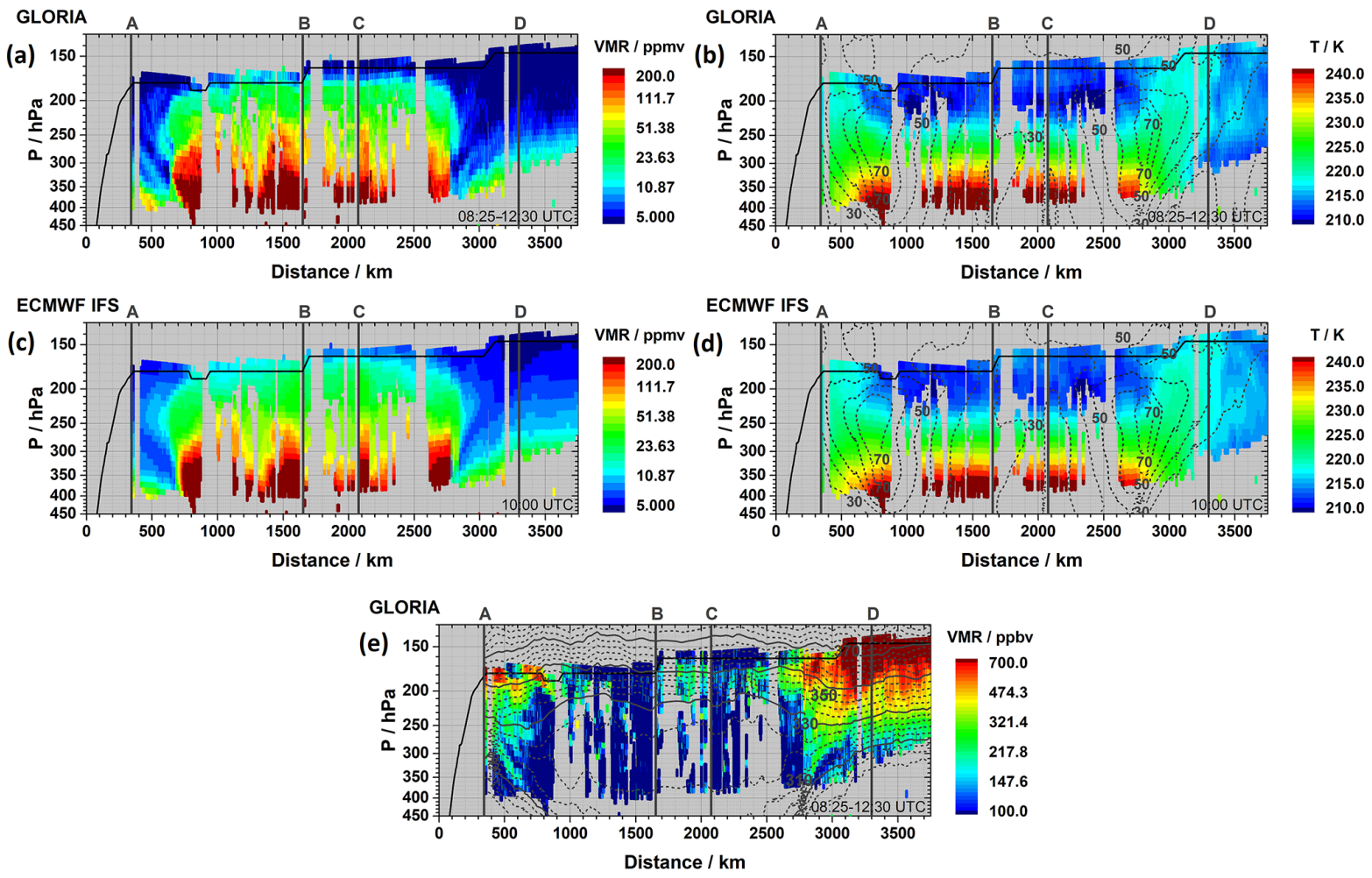

Figure 8. GLORIA observations of water vapour mixing ratio (a), absolute temperature (b), and ozone mixing ratio (e) along two passages of the tropopause fold. IFS water vapour mixing ratio (c) and temperature (d) interpolated to the GLORIA tangent points. IFS horizontal wind $V_{\mathrm{H}}\left(\mathrm{m} \mathrm{s}^{-1}\right.$, dashed lines, $\left.\Delta V_{\mathrm{H}}=10 \mathrm{~m} \mathrm{~s}^{-1}\right)$ is superimposed on (b) and (d), GLORIA potential temperature $\Theta$ (K, solid and dashed lines, $\Delta \Theta=4 \mathrm{~K}$ ) on (e). Bold solid lines in all panels mark HALO's flight levels. Waypoints mentioned in the text are denoted by A, B, C, and $\mathrm{D}$.

$T<215 \mathrm{~K}$ (maybe wave-induced) and clouds (blocked areas in Fig. 8a, b, and e) point to non-adiabatic processes such as radiative cooling and cloud formation.

The corresponding IFS cross sections of water vapour and temperature taken at 10:00 UTC and interpolated to the GLORIA tangent points already reveal a remarkable agreement with the GLORIA observations (Fig. 8c, d). The tropopause fold is identified at the same position as in the GLORIA observations and its vertical and horizontal extents are similar to the observations. However, the $\mathrm{H}_{2} \mathrm{O}$ values inside the fold are higher and the observed separated dry filaments are missing in the IFS data. Although the structure of the tropospheric water vapour distribution is well represented by the IFS, there are notable deviations from the GLORIA observations. In particular, the IFS simulates much smaller vertical $\mathrm{H}_{2} \mathrm{O}$ gradients in the transition zone from tropospheric to stratospheric air near the tropopause. Furthermore, higher water vapour mixing ratios reach up to higher altitudes and the very dry stratospheric air sensed by GLORIA north of PFJ is only partly reproduced. The comparison of GLORIA's temperature with the IFS field shows a remarkable agreement (Fig. 8b, d). Again, local deviations occur. For example, the observed temperature maximum around flight al- titude at a distance of about $700 \mathrm{~km}$ and the cold spots south of the tropopause fold are reproduced moderately by the IFS.

\subsection{Mesoscale fine structure}

The IFS data used to compare with the GLORIA observations as shown in Fig. 8 were interpolated directly to the tangent points. However, in the presence of horizontal $\mathrm{H}_{2} \mathrm{O}$ and temperature gradients and mesoscale fine structures along GLORIA's line-of-sight view, the horizontal smoothing characteristics of GLORIA may affect the comparison significantly. Therefore, we apply the observational filter in the following to sample the IFS data as outlined in Sect. 2.3. Figure $9 \mathrm{a}$ and $\mathrm{b}$ display close-ups of the retrieved water vapour distributions along the tropopause fold during the south- and northbound legs, respectively. In the same way, Fig. 9e and $\mathrm{f}$ show the ozone distributions.

Essentially, Fig. 9 juxtaposes snapshots of a tropopause fold at two different stages of its evolution which are separated by about $2.5 \mathrm{~h}$ and sampled in different viewing directions. GLORIA water vapour and ozone measurements show remarkably well-resolved signatures of stratospheretroposphere exchange: tongues of dry and ozone-rich stratospheric air intrude deeply into the troposphere (Fig. 9a, e). 

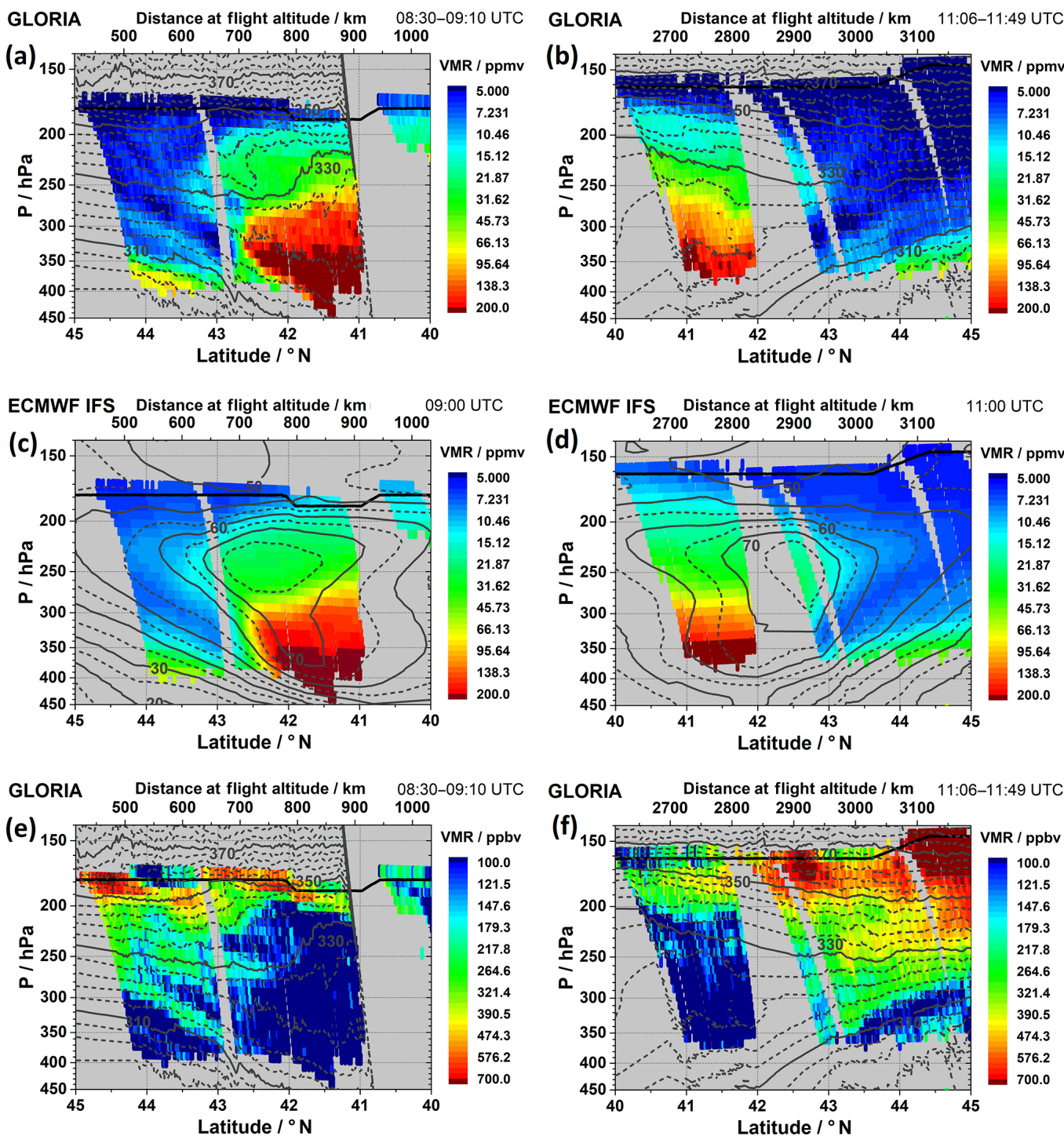

Figure 9. GLORIA observations of water vapour mixing ratio (a-b) and of ozone mixing ratio (e-f) for the southbound leg (a, c, e) and the northbound leg (b, d, f), respectively. Superimposed on panels (a), (b), (e), and (f) is potential temperature $\Theta(\mathrm{K}$, solid and dashed grey lines, $\Delta \Theta=4 \mathrm{~K}$ ), derived from GLORIA temperature observations and HRES background pressure. Panels (c) and (d): IFS water vapour mixing ratio sampled using GLORIA observational filters. Horizontal wind $V_{\mathrm{H}}\left(\mathrm{m} \mathrm{s}^{-1}\right.$, solid and dashed grey lines, $\left.\Delta V_{\mathrm{H}}=5 \mathrm{~ms} \mathrm{~s}^{-1}\right)$ is superimposed on (c) and (d). Bold solid lines in all panels mark HALO's flight levels.

The observed distribution of the potential temperature reveals descending isentropes in agreement with the conceptual view of the processes inside the tropopause fold. Simultaneously, moist tropospheric air with low ozone values is entrained into the stratosphere. This happens in the vicinity of and above the core of the PFJ above about $280 \mathrm{hPa}$ where the isentropic surfaces are folded and indicate mixing processes (Fig. 9a, e); see Sect. 5.4. In contrast, the sharper horizontal $\mathrm{H}_{2} \mathrm{O}$ gradients at the southern and lower side of the tropopause fold are indicative of advective processes extruding dry stratospheric air down. During the second passage, essentially the same overall structure of the tropopause fold was observed (Fig. 9b, f). However, the intruding filaments of low $\mathrm{H}_{2} \mathrm{O}$ and high ozone are much fainter inside the fold. Furthermore, the water vapour distribution in the jet stream region appears notably smoother. Again, a sharp contrast towards tropospheric water vapour is found in the lower compartment of the fold at the anticyclonic side. (Fig. 9b). The GLORIA observations as presented in Fig. 9a, b, e, and $\mathrm{f}$ are the first combined temperature and trace gas observations resolving a horizontally and vertically extended active mixing region belonging to a tropopause fold.

Figure 9c and $\mathrm{d}$ juxtapose the IFS water vapour fields using the respective observational filters $\widetilde{\mathbf{A}}$ at 09:00 and 

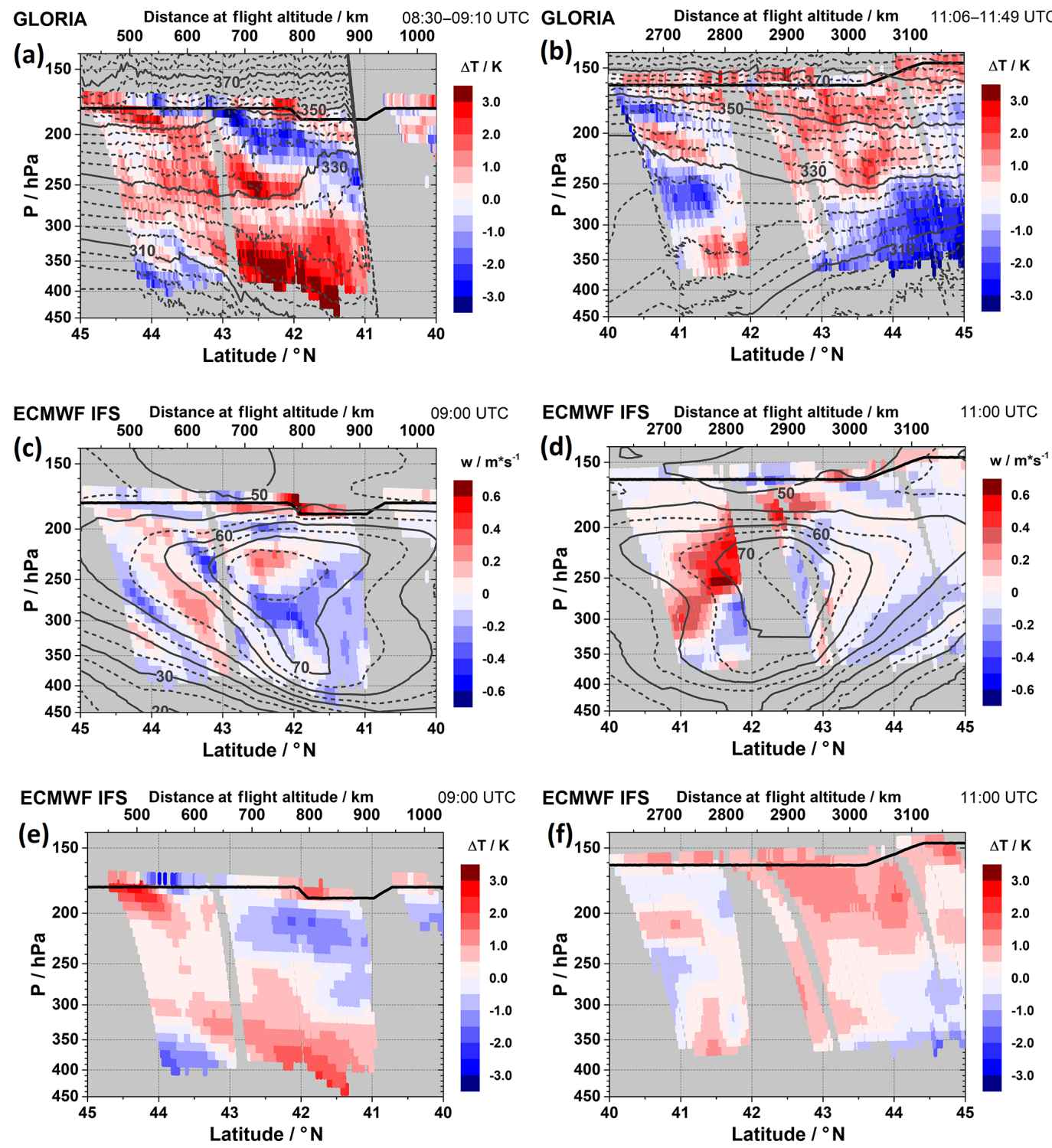

Figure 10. Temperature perturbations $\Delta T(\mathrm{~K}$, colour coded $)$ and $\Theta(\mathrm{K}$, solid and dashed grey lines, $\Delta \Theta=4 \mathrm{~K})$ as derived from GLORIA's temperature measurements $(\mathbf{a}, \mathbf{b})$, IFS vertical wind $\left(\mathrm{m} \mathrm{s}^{-1}\right.$, colour-coded) and $V_{\mathrm{H}}\left(\mathrm{m} \mathrm{s}^{-1}\right.$, solid and dashed grey lines, $\left.\Delta V_{\mathrm{H}}=5 \mathrm{~m} \mathrm{~s}{ }^{-1}\right)$ at GLORIA tangent points (c, d), and IFS temperature perturbations $\Delta T$ (K, colour-coded) sampled using GLORIA observational filters (e, f) for the southbound leg (a, $\mathbf{c}, \mathbf{e})$ and the northbound leg $(\mathbf{b}, \mathbf{d}, \mathbf{f})$, respectively. Bold solid lines in all panels mark HALO's flight levels.

11:00 UTC, respectively. The application of the observational filters improves the agreement with GLORIA observations significantly (see Appendix A). Overall, the IFS water vapour distributions agree remarkably with the GLORIA observations. The tropopause fold is wrapped around the jet stream and is found at the same position as in the observation, and its overall shape compares well to the GLORIA measurements. However, the IFS fields appear to be too moist in the stratosphere and the very low $\mathrm{H}_{2} \mathrm{O}$ values as observed by GLORIA were not reproduced. Furthermore, a smoother transition from tropospheric towards stratospheric mixing ratios is found in the IFS data. In spite of the rather high spatial resolution of the global IFS data, the filamentary structure inside the tropopause fold is not resolved.

\subsection{Mountain-wave-induced temperature perturbations}

Figure 10a and $\mathrm{b}$ display the observed temperature perturbations (versus IFS background temperatures; see Sect. 2.2) and the potential temperature along the south- and northbound legs, respectively. During the first passage of the tropopause fold, the GLORIA observations show large temperature perturbations exceeding $\pm 3 \mathrm{~K}$, whereas their val- 
ues are slightly lower and mostly do not exceed $\pm 2 \mathrm{~K}$ during the second passage on the northbound leg. Below about $300 \mathrm{hPa}$, the temperature perturbations reflect the large-scale meridional temperature gradient discussed above in relation to Fig. 8b: warm anomalies are located to the south, cold anomalies to the north. Above that level, the meridional gradient of absolute temperature reverses sign (Fig. 8b) and this is generally reflected here by warm temperature anomalies in the north and cold ones to the south (Fig. 10a and b). Moreover, there are alternating patterns of positive and negative temperature perturbations above about $300 \mathrm{hPa}$ which indicate the presence of mountain waves. On the southbound leg, their phase lines extend from 45 to about $41^{\circ} \mathrm{N}$, whereas on the northbound leg they are restricted to the segment from 40 to $42^{\circ} \mathrm{N}$ when HALO approached the Italian peninsula from the south again (Fig. 5).

As mentioned above, HALO flew nearly parallel to the phase lines of the vertically propagating mountain waves. This was confirmed by the IFS phase line orientations as documented in Fig. 5 and also by recent high-resolution numerical simulations presented in Fig. 11 in Bramberger et al. (2018). Therefore, the observed tilt of the phase lines and their changing vertical wavelength are related to the different propagation conditions in terms of wind and stability along the flight track. In particular, the temperature perturbations along the southbound leg show nearly horizontal orientation inside the core of the PFJ at around $42^{\circ} \mathrm{N}$. In this segment the largest temperature fluctuations were observed and they are related to the sudden and dramatic change of temperature and meridional wind at flight level which resulted in the stall event and the subsequent forced descent of HALO (Bramberger et al., 2018).

The vertical wind of the IFS short-term forecasts provides indication of the secondary circulation around the core of the PFJ. While the vertical velocity along the northbound leg (Fig. 10d) reveals nearly undisturbed upwelling south and downwelling north of the PFJ as expected, the vertical flow field is heavily disturbed along the southbound leg (Fig. 10c). There again, stacked alternating positive and negative values indicate the presence of mountain waves.

In the IFS data, the temperature perturbations mainly reflect the large-scale meridional temperature gradient (Fig. 10e and f). As shown in Appendix A, particularly for temperature, the application of the observational filter strongly improves the agreement with the GLORIA observations. Their amplitudes are, however, generally weaker than in the GLORIA observations. Exceptionally, the vertical structure of the temperature fluctuations north of the stall event around $500 \mathrm{~km}$ is well represented, indicating that the IFS captured the vertically propagating mountain waves at least partially. Overall, the IFS temperature perturbations reproduce the major structures found in the GLORIA data well. Temperature amplitudes are typically weaker by $\sim 1 \mathrm{~K}$, and less fine structures are identified.

\subsection{Mixing in the vicinity of the tropopause fold}

Figure 11a-d show the tracer-tracer correlations of GLORIA observations between 40 and $45^{\circ} \mathrm{N}$ as functions of potential temperature in different views. These plots include simultaneous GLORIA observations of water vapour, ozone, and potential temperature covering an altitude range of about $6 \mathrm{~km}$ below HALO's flight level. As expected, higher ozone values are correlated with low $\mathrm{H}_{2} \mathrm{O}$ values and characterize the stratospheric tracer distribution along the vertical axis. Conversely, low ozone and high $\mathrm{H}_{2} \mathrm{O}$ values represent the tropospheric tracer distribution along the horizontal axis (Fig. 11a, c and d). In general, the potential temperature follows the altitude dependence, i.e. lower $\Theta$ values are associated with high $\mathrm{H}_{2} \mathrm{O}$ values and low $\mathrm{O}_{3}$ values, and vice versa. Maximum water vapour values appear at the intermediate range of $310 \mathrm{~K}<\Theta<330 \mathrm{~K}$, marking high tropospheric mixing ratios sampled south of the tropopause fold (compare Fig. 11b with high mixing ratios and isentropes south of the tropopause fold in Fig. 11e and f). Low $\mathrm{H}_{2} \mathrm{O}$ values in Fig. $11 \mathrm{a}-\mathrm{d}$ around $\Theta=310$ and $320 \mathrm{~K}$ correspond to the stratospheric water vapour mixing ratios within the lower compartment of the tropopause fold, while the slightly enhanced $\mathrm{H}_{2} \mathrm{O}$ values (up to $\sim 50 \mathrm{ppmv}$ ) below $\Theta=310 \mathrm{~K}$ mark the upper troposphere at the north of the tropopause fold (cf. Fig. 11b, e, and f).

Classically, the tracer relationship is used to define the provenance of the sampled air masses. Gettelman et al. (2011) used $\mathrm{H}_{2} \mathrm{O}$ mixing ratios of less than about $12 \mathrm{ppmv}$ as a threshold for stratospheric air and ozone values of less than about 65 ppbv as a threshold for tropospheric air. The respective thresholds are added in Fig. 11a, c, and d. This means that data points which are close to both tracer axes of the diagrams in Fig. 11a-d indicate an atmospheric state with no mixing and belonging either to the stratosphere or the troposphere (e.g. Plumb, 2007; Gettelman et al., 2011). Data outside these regions are called mixed regions of the ExTL. Typical aircraft observations of stratospheretroposphere mixing along vertically stacked flight legs appear in such diagrams as so-called mixing lines connecting both reservoirs; see Fig. 11 in Gettelman et al. (2011). Here, the close-up image of the GLORIA observations along the individual legs reveals a widespread mixing area without individual mixing lines. These observations indicate active stratosphere-troposphere exchange in the vicinity of the tropopause fold. Between 330 and $350 \mathrm{~K}$ in particular, we find enhanced water vapour values, which are accompanied by notably enhanced ozone volume mixing ratios above 200 ppbv (Fig. 11b, c, and d). However, slightly enhanced ozone values up to $200 \mathrm{ppbv}$, which are accompanied by enhanced $\mathrm{H}_{2} \mathrm{O}$ well above 20 ppmv, are found, particularly below $330 \mathrm{~K}$. The change in the shape of the mixing region with potential temperature is visualized in Fig. $11 \mathrm{~b}$ by colourcoding only data points falling into the 2-D mixing area. 
(a)
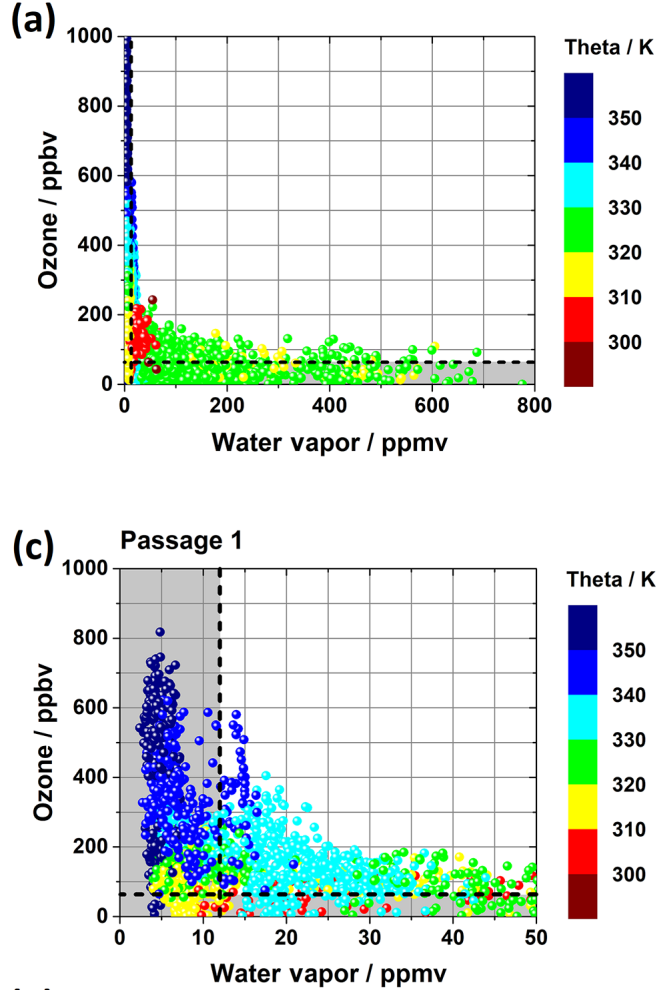

(e)

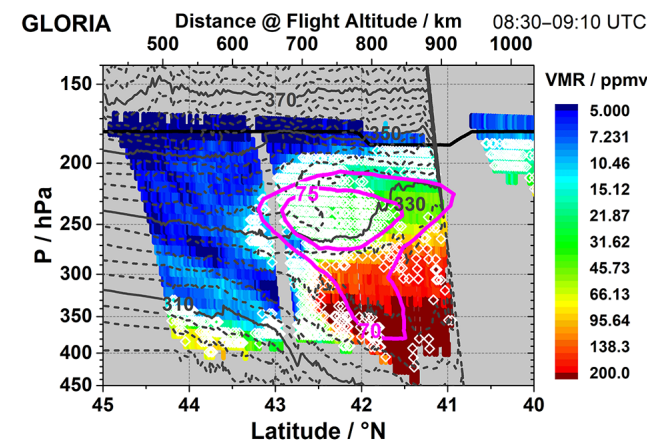

(b)
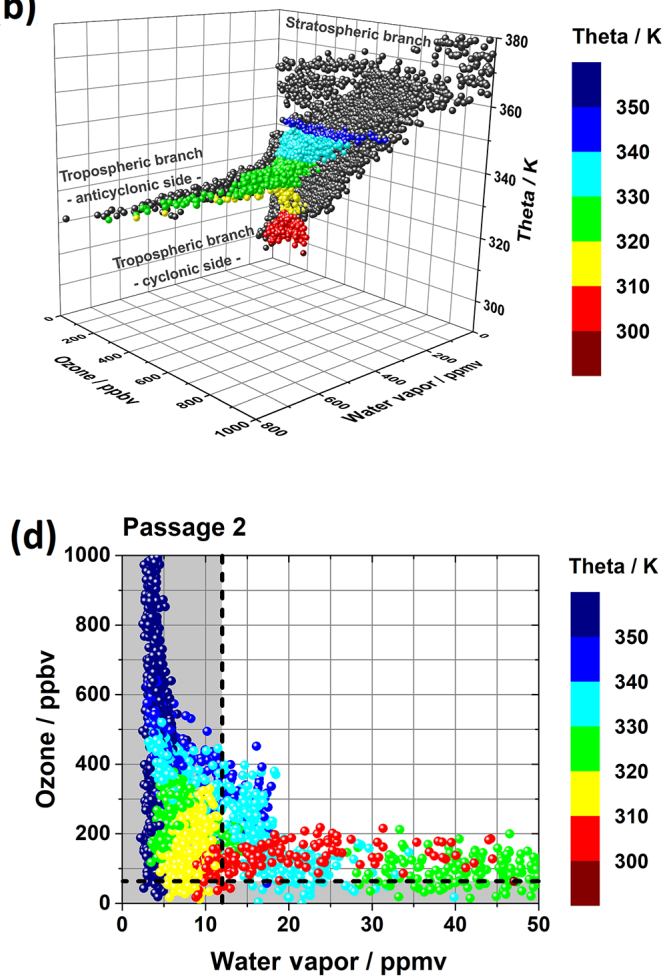

(f)

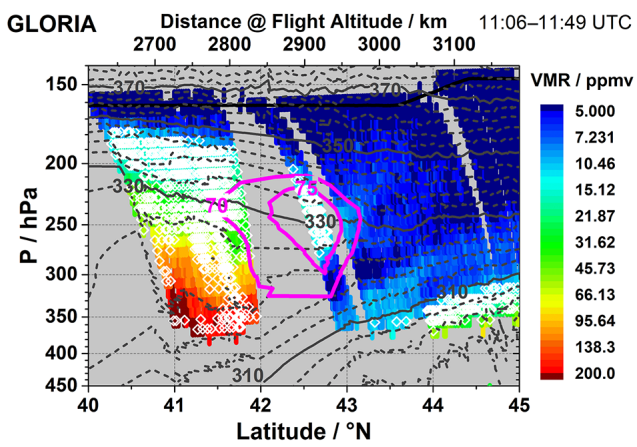

Figure 11. Tracer-tracer correlations of GLORIA's water vapour and ozone profiles during both tropopause fold passages as function of the observed potential temperatures. All observational data along south- and northbound passages are included in the 2-D and 3-D illustrations in panels (a) and (b). Panels (c) and (d) display the southbound and northbound passage observations separately. Panels (e) and (f) show GLORIA water vapour (as in Fig. 9a and b), with data points characterized by ozone $>65$ ppbv and water vapour $>12$ ppmv marked by white diamonds (cf. dashed black lines in panels (a), (c), and (d); colour-coded points in panel (b); and Gettelmann et al., 2011, their Sect. 4.3). $\Theta(\mathrm{K}$, solid and dashed grey lines, $\Delta \Theta=4 \mathrm{~K})$ as derived from GLORIA's temperature and IFS horizontal wind $V_{\mathrm{H}}\left(\mathrm{m} \mathrm{s}^{-1}\right.$, bold magenta lines) are superimposed in panels (e) and (f).

To illustrate the locations of the mixing regions, data points indicative for the ExTL mixing region (water vapour $>12$ ppmv and ozone $>65$ ppmv) are flagged in the vertical cross section displayed in Fig. 11e and f. Particularly, the data points with $\Theta$ values between 330 and $350 \mathrm{~K}$, sticking out most of all in the correlations (data points with ozone up to $400 \mathrm{ppbv}$ and more at water vapour well above $12 \mathrm{ppmv})$, show compact distributions above the PFJ core which are tilted towards the fold. This suggests that the secondary cir- culation around the core of the PFJ (see Fig. 10c and d) entrains moist air from the troposphere at the anticyclonic side and mixes it into the stratosphere. Vice versa, the flagged data points characterized by lower $\Theta$ values below the PFJ core in Fig. 11e indicate mixing of stratospheric air masses into the troposphere due to advection and filamentation, probably intensified by the PFJ secondary circulation. Here, and also in the ExTL mixing region south of the tropopause fold, only weaker enhancements of ozone up to $\sim 200 \mathrm{ppbv}$ 
are found for the data points attributed to the mixing zone. In Fig. 11f, the dense mixing region in the lower compartment of the fold is missing, probably due to the data gap between 42 and $43^{\circ} \mathrm{N}$. Figure $11 \mathrm{~b}$ reveals how the mixing region changes, like on a spiral stair, from a predominantly tropospheric correlation (low ozone, strongly variable water vapour) below $330 \mathrm{~K}$ to a predominantly stratospheric correlation (low water vapour, more variable ozone). Thereby, the $330 \mathrm{~K}$ isentrope roughly separates the regions of stratosphere-to-troposphere and troposphere-to-stratosphere exchange.

The ExTL mixing zone during the first passage of the tropopause fold is notably disturbed by the mountain wave (see Fig. 11e). The wave-induced temperature anomaly (Fig. 10a) results in a distortion and spreading of the isentropic bands in the mixing zone between 41.5 and $43^{\circ} \mathrm{N}$ above $270 \mathrm{hPa}$. This coincides with the clear air turbulence mixing region in the vicinity of the jet stream core (Shapiro, 1980) and suggests that ongoing mixing processes are altered. Moreover, the temperature anomaly results in a steepening and overturning of isentropes. The consequence is a region of convective instability, which further supports turbulence and mixing. When compared to the mixing zone associated with a tropopause fold near the subtropical jet stream in July 2006 analysed by Ungermann et al. (2013), a larger mixing region stretching deeper into the jet stream core is observed here. The large extent of the observed mixing zone thus might be a consequence of the interaction with the mountain wave.

Another interesting detail is found when Figs. 10c and 11e are compared: the separated narrow moist filament attributed to the mixing zone between $\sim 43.5^{\circ} \mathrm{N}(250 \mathrm{hPa})$ and $\sim 42.5^{\circ} \mathrm{N}(320 \mathrm{hPa})$ (Fig. 11e) coincides with the position and alignment of a region of wave-induced wind shear (Fig. 10c). While advection within the tropopause fold probably is the main driver for the formation of the filaments, the wave-induced wind shear is likely to enhance mixing processes here. Further complex patterns of the data points at the lower southern side of the PFJ attributed to the mixing zone are interpreted as being produced by the complex dynamics and mixing processes around the PFJ.

\section{Conclusions}

This paper reports findings of remote-sensing observations of a tropopause fold by means of the GLORIA instrument aboard the German research aircraft HALO over northern Italy on 12 January 2016. The design of the chosen flight tracks crossing the PFJ meridionally provided the opportunity to observe the deep intrusion of stratospheric air in a tropopause fold as well as mountain waves in great detail. In this way, the particular characteristics of the linear GLORIA observations were used to their best advantages: the high spatial resolution along the flight track enabled accurate obser- vations of the predominant large meridional gradients of temperature and trace gases, whereas the lower resolution normal to the flight track sampled air with smaller spatial variability. In this particular configuration, the GLORIA highspectral-resolution measurements are advantageous and extremely valuable as they provide simultaneous vertical profiles of temperature, water vapour, ozone, and potential temperature with high definition.

Our findings comprise the detection of a broad intrusion of dry and ozone-rich stratospheric air. The combination with the IFS wind confirms the accepted conceptual model of a tropopause fold associated with the PFJ. In particular, we detected narrow filaments of water and ozone inside the tropopause fold at the cyclonic shear side of the PFJ that indicate advective processes predominantly forming the stratospheric intrusion. The astonishing detection of such fine filaments by GLORIA was only possible due to the high spatial resolution along the flight track. These observations confirm earlier findings of the stably stratified laminae extruding stratospheric air down to the troposphere (Shapiro et al., 1987). Furthermore, broader tongues of moist air entraining tropospheric air were observed at the southern, anticyclonic shear side of the PFJ. These GLORIA observations in combination with the IFS wind suggest entrainment of moist tropospheric air into the stratosphere by the secondary circulation around the PFJ core. Due to the flow across the Apennines and the nearly parallel alignment of lower and upper tropospheric winds, the tropopause fold was perturbed by vertically propagating mountain waves. The wave signatures are clearly evident in the GLORIA temperature field, and the tracer field shows a displacement of moist tropospheric air deep into the ExTL mixing region above the PFJ. Moreover, the wave-induced temperature modulations found in the GLORIA data approach amplitudes of $\pm 3 \mathrm{~K}$ and result in spreading, steepening, and overturning of isentropes in the PFJ core region, fostering vertical isentropic transport, mixing processes and possibly partial wave breaking.

In contrast to 1-D airborne in situ observations, GLORIA's high-vertical resolution vertical profiles provide an almost complete 2-D sampling of mixing in the vicinity of the PFJ. For this purpose, tracer-tracer correlations of water vapour and ozone were constructed. Here, the common mixing lines are replaced by mixing areas due to the dense vertical coverage of the GLORIA measurements. Specifically, the combination with the measured potential temperature presents a detailed 2-D view of active mixing in the extra-tropical transition region. Mixing takes place in the interval $300 \mathrm{~K}<$ $\Theta<350 \mathrm{~K}$, with stratosphere-to-troposphere exchange taking place predominantly below $330 \mathrm{~K}$ and troposphere-tostratosphere exchange above. Two major locations of mixing were identified: a broad region on the anticyclonic shear side of the PFJ where warm and moist air ascends and entrains air into the stratosphere. The other active mixing region is located at the lower edge of the tropopause fold where vertical 
shear and differential advection leads to mechanical turbulence production.

Finally, the GLORIA observations validated the shortterm forecasts of the high-resolution IFS. The agreement of the overall features of the tropopause fold such as location, shape, and vertical and horizontal extents is astonishing. Naturally, the IFS cannot reproduce the sharp gradients at the edges and the filaments inside the tropopause fold. Furthermore, the fine structure of the mixing region was not reproduced even with the $9 \mathrm{~km}$ horizontal resolution of the IFS that was used here, and a smoother transition of high tropospheric water vapour mixing ratios into the stratosphere was found at the anticyclonic shear side of the PFJ. The application of GLORIA's observational filters instead of interpolation of the model data directly at the tangent points clearly improves the agreement with the remote-sensing data. Overall, the combination of the GLORIA and IFS data provides a detailed view of a tropopause fold, resolves an active mixing region, and suggests that mountain wave perturbations have the potential to modulate exchange processes in the vicinity of tropopause folds.

Data availability. The GLORIA remote sensing and BAHAMAS in situ data are available at the HALO database (https://doi.org/ 10.17616/R39Q0T, HALO consortium, last access: 10 October 2018). The ECMWF IFS and HRES data are freely accessible at the ECMWF website (https://www.ecmwf.int/, ECMWF, last access: 10 October 2018). The radiosonde data were accessed at the Wyoming Atmospheric Soundings website (Department of Atmospheric Science, University of Wyoming, USA, http://weather. uwyo.edu/upperair/sounding.html, last access: 10 October 2018). 


\section{Appendix A}
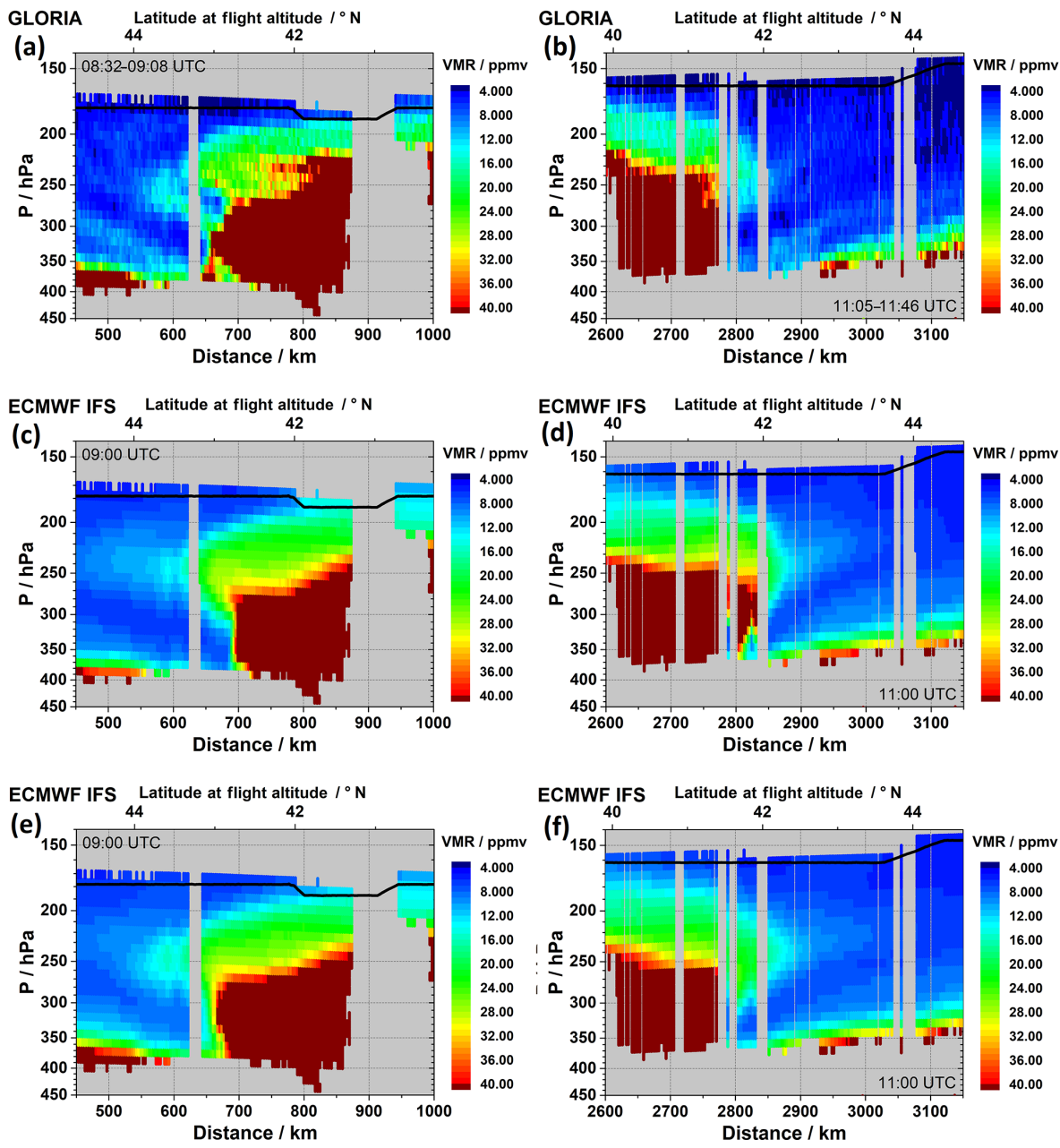

Figure A1. GLORIA water vapour (a, b) and IFS water vapour sampled at GLORIA tangent points (c, d) and using GLORIA observational filters (e, f). Black line in all panels: flight level.

Figure A1 shows the comparison of the GLORIA water vapour observations during both tropopause fold passages (panels $a, b$ ) together with the IFS data sampled at the GLORIA tangent points (panels c, d) and using the GLORIA observational filters $\widetilde{\mathbf{A}}$ (panels e, f). The overall pattern and the absolute water vapour mixing ratios are very similar due to the propitious viewing geometry along the fold. However, several details show a better agreement with the GLORIA observations after application of the observational filter: higher mixing ratios are found in Fig. Ale between 450 and $550 \mathrm{~km}$ around $400 \mathrm{hPa}$, and the extent of the lower compartment of the tropopause fold to the south compares better with the GLORIA observations. Also, during the second passage, the shape and extent of the lower compartment to the south agree better with GLORIA.
Figure A2 shows the corresponding temperature residuals derived from the GLORIA observations during both tropopause fold passages (panels $a, b$ ) together with the corresponding temperature residuals retrieved from the IFS data. Again, the IFS data are sampled at the GLORIA tangent points (panels c, d) and using the GLORIA observational filters $\widetilde{\mathbf{A}}$ (panels e, f). Here, the application of the observational filters strongly improves the agreement with the GLORIA observations. The IFS data sampled at the GLORIA tangent points show hardly any agreement with the patterns found in the GLORIA data. In particular, during the change in the flight level (see Bramberger et al., 2018), the IFS data at the GLORIA tangent points show negative temperature residuals in accordance with the in situ observations (see Fig. 7b), while the GLORIA observations show a temperature maximum (see Sect. 4.1). The application of the observational filter resolves this apparent discrepancy (Fig. A2e), and a lo- 

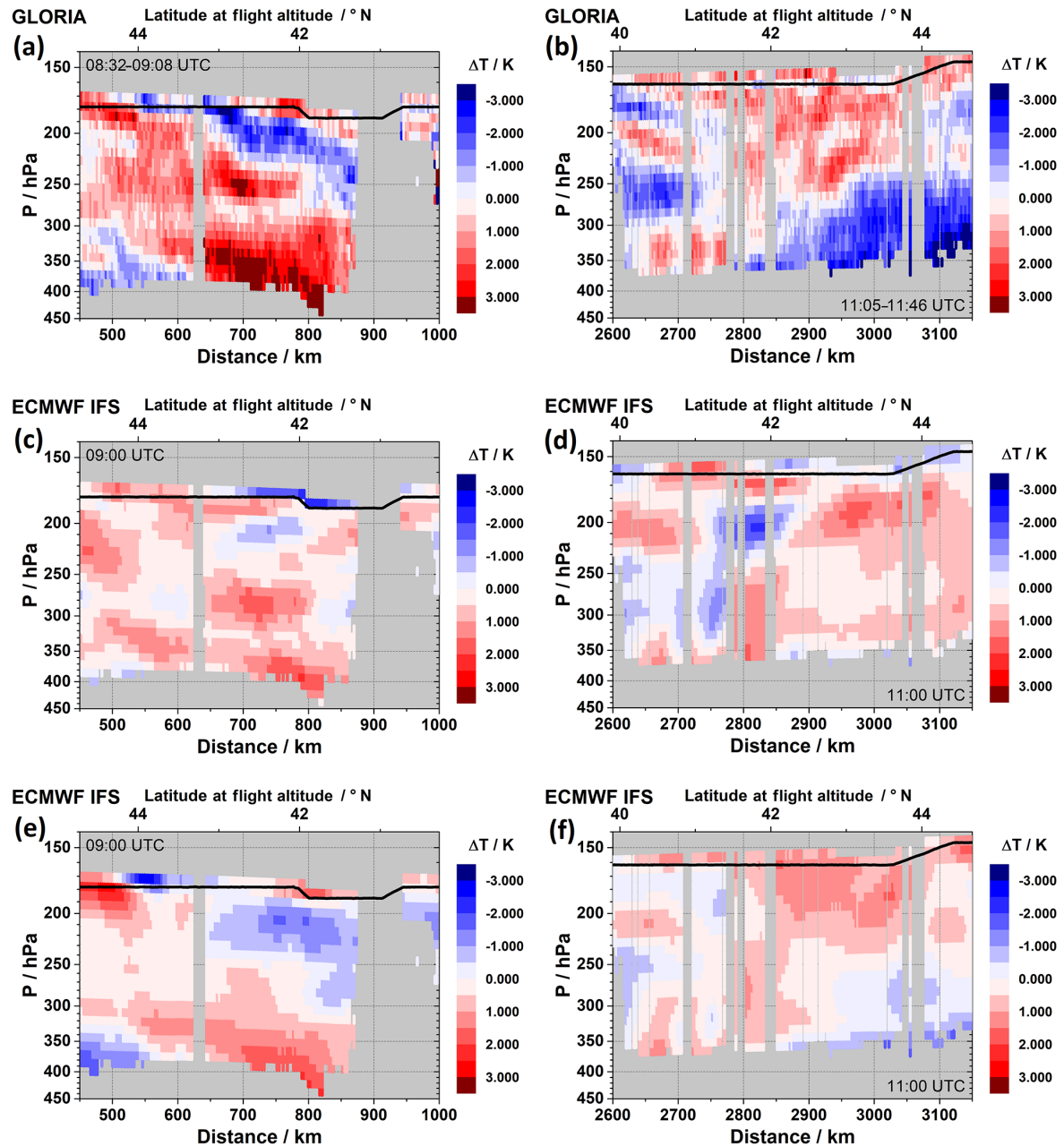

Figure A2. GLORIA residual temperature (a, b) and IFS residual temperature sampled at GLORIA tangent points (c, d) and using GLORIA observational filters (e, f). Black line in all panels: flight level.

cal temperature maximum as in the GLORIA data is found (Fig. A2a). Also, the developed maximum-minimum structure in the GLORIA data between 450 and $600 \mathrm{~km}$ at flight altitude is reproduced remarkably well after application of the observational filter, while this structure is not found in the IFS data sampled at the GLORIA tangent points. Also, during the second passage, improved agreement between the GLORIA and IFS data is found when the IFS data are sampled using the observational filter. While the IFS data at the GLORIA tangent points (Fig. A2d) show a notable local temperature minimum at a distance of $2800 \mathrm{~km}$ not seen in the GLORIA data (Fig. A2b), this structure disappears after application of the observational filter (Fig. A2f).

The fact that only a moderate improvement of the agreement is found in the case of water vapour and a strong improvement in the case of the temperature residuals can be understood by considering the zonal vertical cross sections of the IFS data shown in Fig. 6. While in the case of water vapour (Fig. 6a) comparably homogeneous conditions were present along the GLORIA viewing direction, sequences of strong temperature modulations are found in the IFS data within a few tens of kilometres (Fig. 6b). Thus, sampling of the IFS data at single points may capture local extremal values, while the application of the observational filters (see Fig. 2) takes into account the horizontal smoothing intrinsic to the GLORIA limb observations and improves the quality of the comparison considerably. 
Author contributions. WW and AD conceived the study and wrote the manuscript. WW, AD and MB performed the analyses. FFV coordinated the GLORIA operations. MH and FH made the compilation of the 2-D averaging kernels possible. SJ performed the GLORIA retrievals. EK operated GLORIA during PGS06. TL and JU performed the level 1 processing of the GLORIA data. HO, BMS and WW coordinated the HALO activities during PGS. All authors assisted with the interpretation of the results and commented the study.

Competing interests. The authors declare that they have no conflict of interest.

Special issue statement. This article is part of the special issues "Sources, propagation, dissipation and impact of gravity waves (ACP/AMT inter-journal SI)" and "The Polar Stratosphere in a Changing Climate (POLSTRACC) (ACP/AMT inter-journal SI)". It is not associated with a conference.

Acknowledgements. This work was supported by the German research initiative ROMIC (Role of the Middle Atmosphere in Climate) and funded by the German Ministry of Research and Education (BMBF) project "Investigation of the life cycle of gravity waves" (GW-LCYCLE, subproject 2, 01LG1206B). This work was furthermore supported by the German Research Foundation (Deutsche Forschungsgemeinschaft, DFG Priority Program SPP 1294). Florian Haenel has received funding from the DFG project no. WO 2160/1-1. Sören Johansson has received funding from the European Community's Seventh Framework Programme (FP7/2007-2013) under grant agreement 603557. We are grateful to the GLORIA team and DLR-FX for performing the measurements and HALO flights during PGS. We thank Andreas Giez and the BAHAMAS-Team of DLR-FX for providing the BAHAMAS data. The campaign was furthermore supported by the GWEX project (Technical Assistance for the Deployment of the GLORIA instrument during the Gravity Wave Experiment, ESA contract no. 4000115111/15/NL/FF/ah). We thank the European Centre for Medium-Range Weather Forecasts (ECMWF) for providing the meteorological data. We acknowledge Wyoming Atmospheric Soundings (Department of Atmospheric Science, University of Wyoming, USA) for providing the radiosonde data (see http://weather.uwyo.edu/upperair/sounding.html, last access: 10 October 2018). We acknowledge support by Deutsche Forschungsgemeinschaft and Open Access Publishing Fund of Karlsruhe Institute of Technology.

The article processing charges for this open-access publication were covered by a Research

Centre of the Helmholtz Association.

Edited by: Jörg Gumbel

Reviewed by: John Gille and one anonymous referee

\section{References}

Alexander, M. J., Geller, M., McLandress, C., Polavarapu, S., Preusse, P., Sassi, F., Sato, K., Eckermann, S., Ern, M., Hertzog, A., Kawatani, Y., Pulido, M., Shaw, T. A., Sigmond, M., Vincent, R., and Watanabe, S.: Recent developments in gravity-wave effects in climate models and the global distribution of gravitywave momentum flux from observations and models, Q. J. Roy. Meteor. Soc., 136, 1103-1124, https://doi.org/10.1002/qj.637, 2010.

Bramberger, M., Dörnbrack, A., Wilms, H., Gemsa, S., Raynor, K., and Sharman, R. D.: Vertically Propagating Mountain Waves - A Hazard for High-Flying Aircraft?, J. Appl. Meteorol. Clim., 57, 1957-1975, https://doi.org/10.1175/JAMC-D-17-0340.1, 2018.

Browell, E. V., Danielsen, E. F., Ismail, S., Gregory, G. L., and Beck, S. M.: Tropopause fold structure determined from airborne lidar and in situ measurements, J. Geophys. Res., 92, 2112-2120, 1987.

Buss, S., Hertzog, A., Hostettler, C., Bui, T. B., Lüthi, D., and Wernli, H.: Analysis of a jet stream induced gravity wave associated with an observed ice cloud over Greenland, Atmos. Chem. Phys., 4, 1183-1200, https://doi.org/10.5194/acp-4-1183-2004, 2004.

Danielsen, E. F.: Project Springfield Report, Tech. Rep. 1517, Defense At. Supp. Agency, Washington, DC, 110 pp., 1964.

Danielsen, E. F.: Stratospheric-tropospheric exchange based on radioactivity, ozone and potential vorticity, J. Atmos. Sci., 25, 502518,1968 .

Danielsen, E. F. and Mohnen, V. A.: Project Duststorm report: ozone transport, in situ measurements and meteorological analyses of tropopause folding, J. Geophys. Res., 82, 5867-5877, 1977.

Dörnbrack, A., Gisinger, S., Pitts, M. C., Poole, L. R., and Maturilli, M.: Multilevel Cloud Structures over Svalbard, Mon. Weather Rev., 145, 1149-1159, https://doi.org/10.1175/MWRD-16-0214.1, 2017.

Dritschel, D. G. and McIntyre, M. E.: Multiple Jets as PV Staircases: The Phillips Effect and the Resilience of Eddy-Transport Barriers, J. Atmos. Sci., 65, 855-874, https://doi.org/10.1175/2007JAS2227.1, 2008.

ECMWF website: ECMWF, 2018, available at: https://www. ecmwf.int/, last access: 10 October 2018.

Ehard, B., Malardel, S., Dörnbrack, A., Kaifler, B., Kaifler, N., and Wedi, N.: Comparing ECMWF high resolution analyses to lidar temperature measurements in the middle atmosphere, Q. J. Roy. Meteor. Soc., 144, 633-640, https://doi.org/10.1002/qj.3206, 2018.

Ehret, G., Hoinka, K. P., Stein, J., Fix, A., Kiemle, C., and Poberaj, G.: Low-stratospheric water vapor measured by an airborne DIAL, J. Geophys. Res., 104, 31351-31359, 1999.

Ern, M., Trinh, Q. T., Preusse, P., Gille, J. C., Mlynczak, M. G., Russell III, J. M., and Riese, M.: GRACILE: a comprehensive climatology of atmospheric gravity wave parameters based on satellite limb soundings, Earth Syst. Sci. Data, 10, 857-892, https://doi.org/10.5194/essd-10-857-2018, 2018.

Fischer, H., Birk, M., Blom, C., Carli, B., Carlotti, M., von Clarmann, T., Delbouille, L., Dudhia, A., Ehhalt, D., Endemann, M., Flaud, J. M., Gessner, R., Kleinert, A., Koopman, R., Langen, J., López-Puertas, M., Mosner, P., Nett, H., Oelhaf, H., Perron, G., Remedios, J., Ridolfi, M., Stiller, G., and Zander, R.: MI- 
PAS: an instrument for atmospheric and climate research, Atmos. Chem. Phys., 8, 2151-2188, https://doi.org/10.5194/acp-8-21512008, 2008.

Flentje, H., Dörnbrack, A., Ehret, G., Fix, A., Kiemle, C., Poberaj, G., and Wirth, M.: Water vapor heterogeneity related to tropopause folds over the North Atlantic revealed by airborne water vapor differential absorption lidar, J. Geophys. Res., 110, D03115, https://doi.org/10.1029/2004JD004957, 2005.

Friedl-Vallon, F., Gulde, T., Hase, F., Kleinert, A., Kulessa, T., Maucher, G., Neubert, T., Olschewski, F., Piesch, C., Preusse, P., Rongen, H., Sartorius, C., Schneider, H., Schönfeld, A., Tan, V., Bayer, N., Blank, J., Dapp, R., Ebersoldt, A., Fischer, H., Graf, F., Guggenmoser, T., Höpfner, M., Kaufmann, M., Kretschmer, E., Latzko, T., Nordmeyer, H., Oelhaf, H., Orphal, J., Riese, M., Schardt, G., Schillings, J., Sha, M. K., Suminska-Ebersoldt, O., and Ungermann, J.: Instrument concept of the imaging Fourier transform spectrometer GLORIA, Atmos. Meas. Tech., 7, 35653577, https://doi.org/10.5194/amt-7-3565-2014, 2014.

Fritts, D. C. and Alexander, M. J.: Gravity wave dynamics and effects in the middle atmosphere, Rev. Geophys., 41, 1003, https://doi.org/10.1029/2001rg000106, 2003.

Fritts, D. C., Smith, R. B., Taylor, M. J., Doyle, J. D., Eckermann, S. D., Dörnbrack, A., Rapp, M., Williams, B. P., Pautet, P. D., Bossert, K., Criddle, N. R., Reynolds, C. A., Reinecke, P. A., Uddstrom, M., Revell, M. J., Turner, R., Kaifler, B., Wagner, J. S., Mixa, T., Kruse, C. G., Nugent, A. D., Watson, C. D., Gisinger, S., Smith, S. M., Lieberman, R. S., Laughman, B., Moore, J. J., Brown, W. O., Haggerty, J. A., Rockwell, A., Stossmeister, G. J., Williams, S. F., Hernandez, G., Murphy, D. J., Klekociuk, A. R., Reid, I. M., and Ma, J.: The Deep Propagating Gravity Wave Experiment (DEEPWAVE): An Airborne and Ground-Based Exploration of Gravity Wave Propagation and Effects from Their Sources throughout the Lower and Middle Atmosphere, B. Am. Meterol. Soc., 97, 425-453, https://doi.org/10.1175/Bams-D-14$00269.1,2016$.

Geller, M. A., Alexander, M. J., Love, P. T., Bacmeister, J., Ern, M., Hertzog, A., Manzini, E., Preusse, P., Sato, K., Scaife, A. A., and Zhou, T.: A comparison between gravity wave momentum fluxes in observations and climate models, J. Climate, 26, 6383-6405, https://doi.org/10.1175/JCLI-D-12-00545.1, 2013.

Gettelman, A., Hoor, P., Pan, L. L., Randel, W. J., Hegglin, M. I., and Birner, T.: The extratropical upper troposphere and lower stratosphere, Rev. Geophys., 49, RG3003, https://doi.org/10.1029/2011RG000355, 2011.

HALO database: HALO consortium, 2018, available at: https://doi. org/10.17616/R39Q0T, last access: 10 October 2018.

Held, I. M.: Momentum transport by quasi-geostrophic eddies, J. Atmos. Sci. 32, 1494-1497, https://doi.org/10.1175/15200469(1975)032<1494:MTBQGE>2.0.CO;2, 1975.

Heller, R., Voigt, C., Beaton, S., Dörnbrack, A., Giez, A., Kaufmann, S., Mallaun, C., Schlager, H., Wagner, J., Young, K., and Rapp, M.: Mountain waves modulate the water vapor distribution in the UTLS, Atmos. Chem. Phys., 17, 14853-14869, https://doi.org/10.5194/acp-17-14853-2017, 2017.

Hólm, E., Forbes, R., Lang, S., Magnusson, L., and Malardel, S.: New model cycle brings higher resolution, ECMWF Newsletter, No. 147, ECMWF, Reading, UK, 14-19, 2016.

Holton, J. R., Haynes, P. H., McIntyre, M. E., Douglass, A. R., Rood, R. B., and Pfister, L.: Stratosphere-Troposphere Exchange,
Rev. Geophys., 33, 403-439, https://doi.org/10.1029/95rg02097, 1995.

Höpfner, M., Blom, C. E., Echle, G., Glatthor, N., Hase, F., and Stiller, G.: Retrieval simulations for MIPAS-STR measurements, in: Proc. of the Int. Radiation Symp., edited by: Smith, W. L., St. Petersburg, Russia, 24-29 July 2000, DEEPAK Publ., Hampton, Va., 2001.

Johansson, S., Woiwode, W., Höpfner, M., Friedl-Vallon, F., Kleinert, A., Kretschmer, E., Latzko, T., Orphal, J., Preusse, P., Ungermann, J., Santee, M. L., Jurkat-Witschas, T., Marsing, A., Voigt, C., Giez, A., Krämer, M., Rolf, C., Zahn, A., Engel, A., Sinnhuber, B.-M., and Oelhaf, H.: Airborne limb-imaging measurements of temperature, $\mathrm{HNO}_{3}, \mathrm{O}_{3}, \mathrm{ClONO}_{2}, \mathrm{H}_{2} \mathrm{O}$ and CFC-12 during the Arctic winter 2015/2016: characterization, in situ validation and comparison to Aura/MLS, Atmos. Meas. Tech., 11, 4737-4756, https://doi.org/10.5194/amt-11-4737-2018, 2018.

Keyser, D. and Shapiro, M.: A review of the structure and dynamics of upper-level frontal zones, Mon. Weather Rev., 114, 452-499, https://doi.org/10.1175/15200493(1986)114<0452:AROTSA>2.0.CO;2, 1986.

Kleinert, A., Friedl-Vallon, F., Guggenmoser, T., Höpfner, M., Neubert, T., Ribalda, R., Sha, M. K., Ungermann, J., Blank, J., Ebersoldt, A., Kretschmer, E., Latzko, T., Oelhaf, H., Olschewski, F., and Preusse, P.: Level 0 to 1 processing of the imaging Fourier transform spectrometer GLORIA: generation of radiometrically and spectrally calibrated spectra, Atmos. Meas. Tech., 7, 41674184, https://doi.org/10.5194/amt-7-4167-2014, 2014.

Koch, S. E., Jamison, B. D., Lu, C. G., Smith, T. L., Tollerud, E. I., Girz, C., Wang, N., Lane, T. P., Shapiro, M. A., Parrish, D. D., and Cooper, O. R.: Turbulence and gravity waves within an upper-level front, J. Atmos. Sci., 62, 3885-3908, 2005.

Kooi, S., Fenn, M., Ismail, S., Ferrare, R., Hair, J., Browell, E., Notari, A., Butler, C., Burton, S., Simpson, S.: Airborne LIDAR Measurements of Water Vapor, Ozone, Clouds, and Aerosols in the Tropics Near Central America During the TC4 Experiment, 24th International Laser Radar Conference, Boulder, CO, USA, 23-27 June 2008, available at: https://ntrs.nasa.gov/search.jsp? R=20080023791 (last access: 10 October 2018), 2008.

Krautstrunk, M. and Giez, A.: The Transition from FALCON to HALO era airborne atmospheric research, in: Atmospheric Physics, edited by: Schumann, U., Research Topics in Aerospace, Springer Verlag, Berlin, 609-624, https://doi.org/10.1007/978-3-642-30183-4_37, 2012.

Krisch, I., Preusse, P., Ungermann, J., Dörnbrack, A., Eckermann, S. D., Ern, M., Friedl-Vallon, F., Kaufmann, M., Oelhaf, H., Rapp, M., Strube, C., and Riese, M.: First tomographic observations of gravity waves by the infrared limb imager GLORIA, Atmos. Chem. Phys., 17, 14937-14953, https://doi.org/10.5194/acp-17-14937-2017, 2017.

Kühnlein, C.: Clear-air turbulence and gravity waves in a front/jet system, diploma thesis, Univ. of Munich, Munich, Germany, 81 pp., 2006.

Lee S. and Kim, H. K.: The dynamical relationship between subtropical and eddy-driven jets, J. Atmos. Sci., 60, 1490-1503, 2003.

Malardel, S., and Wedi, N. P.: How does subgrid-scale parametrization influence nonlinear spectral energy fluxes in global NWP models?, J. Geophys. Res.-Atmos., 121, 5395-5410, https://doi.org/10.1002/2015JD023970, 2016. 
Martius, O., Schwierz, C., and Davies, H. C.: TropopauseLevel Waveguides, J. Atmos. Sci., 67, 866-879, https://doi.org/10.1175/2009JAS2995.1, 2010.

Nash, J.: Measurement of upper-air pressure, temperature and humidity, Instruments and Observing Methods Report No. 121, World Meteorological Organization, available at: https://www.wmo.int/pages/prog/www/IMOP/publications/ IOM-121_Upper-Air.pdf (last access: 10 October 2018), 2015.

Plumb, R. A.: Tracer interrelationships in the stratosphere, Rev. Geophys., 45, RG4005, https://doi.org/10.1029/2005RG000179, 2007.

Preusse, P., Dörnbrack, A., Eckermann, S. D., Riese, M., Schaeler, B., Bacmeister, J. T., Broutman, D., and Grossmann, K. U.: Space-based measurements of stratospheric mountain waves by CRISTA, 1. Sensitivity, analysis method, and a case study, J. Geophys. Res., 107, 8178, https://doi.org/10.1029/2001JD000699, 2002.

Preusse, P., Ern, M., Eckermann, S. D., Warner, C. D., Picard, R. H., Knieling, P., Krebsbach, M., Russel III, J. M., Mlynczak, M. G., Mertens, C. J., and Riese, M.: Tropopause to mesopause gravity waves in August: measurement and modeling, J. Atmos. Sol.Terr. Phy., 68, 1730-1751, 2006.

Preusse, P., Ern, M., Bechtold, P., Eckermann, S. D., Kalisch, S., Trinh, Q. T., and Riese, M.: Characteristics of gravity waves resolved by ECMWF, Atmos. Chem. Phys., 14, 10483-10508, https://doi.org/10.5194/acp-14-10483-2014, 2014.

Reed, R. J.: A study of a characteristic tpye of upper-level frontogenesis, J. Meteor., 12, 226-237, https://doi.org/10.1175/15200469(1955)012<0226:ASOACT>2.0.CO;2, 1955.

Reed, R. J. and Danielsen, E. F.: Fronts in the vicinity of the tropopause, Arch. Met. Geoph. Biokl. A., 11, 1-17, https://doi.org/10.1007/BF02247637, 1958.

Remedios, J. J., Leigh, R. J., Waterfall, A. M., Moore, D. P., Sembhi, H., Parkes, I., Greenhough, J., Chipperfield, M. P., and Hauglustaine, D.: MIPAS reference atmospheres and comparisons to V4.61/V4.62 MIPAS level 2 geophysical data sets, Atmos. Chem. Phys. Discuss., 7, 9973-10017, https://doi.org/10.5194/acpd-7-9973-2007, 2007.

Riese, M., Oelhaf, H., Preusse, P., Blank, J., Ern, M., Friedl-Vallon, F., Fischer, H., Guggenmoser, T., Höpfner, M., Hoor, P., Kaufmann, M., Orphal, J., Plöger, F., Spang, R., Suminska-Ebersoldt, O., Ungermann, J., Vogel, B., and Woiwode, W.: Gimballed Limb Observer for Radiance Imaging of the Atmosphere (GLORIA) scientific objectives, Atmos. Meas. Tech., 7, 1915-1928, https://doi.org/10.5194/amt-7-1915-2014, 2014.

Rodgers, C. D.: Inverse Methods for Atmospheric Sounding: theory and Practice, in: Series on Atmospheric, Oceanic and Planetary Physics, vol. 2, edited by: Taylor, F. W., World Scientific, Singapore, 2000.

Shapiro, M. A.: Further Evidence of the Mesoscale and Turbulent Structure of Upper Level Jet Stream-Frontal Zone Systems, Mon. Weather Rev., 106, 1100-1111, https://doi.org/10.1175/15200493(1978)106<1100:FEOTMA>2.0.CO;2, 1978.

Shapiro, M. A.: Turbulent Mixing within Tropopause Folds as a Mechanism for the Exchange of Chemical-Constituents between the Stratosphere and Troposphere, J. Atmos. Sci., 37, 994-1004, 1980.
Shapiro, M. A., Reiter, E. R., Cadle, R. D., and W. A. Sedlack: Vertical mass- and trace constituent transports in the vicinity of jet streams, Arch. Met. Geoph. Biokl. B., 28, 193-206, https://doi.org/10.1007/BF02245351, 1980.

Shapiro, M. A., Hampel, T., and Krueger, A. J.: The Arctic Tropopause Fold, Mon. Weather Rev., 115, 444-454, https://doi.org/10.1175/15200493(1987)115<0444:TATF>2.0.CO;2, 1987.

Sharman, R. D., Trier, S. B., Lane, T. P., and Doyle, J. D.: Sources and dynamics of turbulence in the upper troposphere and lower stratosphere: A review, Geophys. Res. Lett., 39, L12803, https://doi.org/10.1029/2012GL051996, 2012.

Spang, R., Remedios, J. J., and Barkley, M. P.: Colour indices for the detection and differentiation of cloud types in infra-red limb emission spectra, Adv. Space Res., 33, 1041-1047, 2004.

Stiller, G. P., von Clarmann, T., Funke, B., Glatthor, N., Hase, F., Höpfner, M., and Linden, A.: Sensitivity of trace gas abundances retrievals from infrared limb emission spectra to simplifying approximations in radiative transfer modelling, J. Quant. Spectrosc. Ra., 72, 249-280, https://doi.org/10.1016/S00224073(01)00123-6, 2002.

Ungermann, J.: Tomographic reconstruction of atmospheric volumes from infrared limb-imager measurements, $\mathrm{PhD}$ thesis, Wuppertal University, 2011.

Ungermann, J., Hoffmann, L., Preusse, P., Kaufmann, M., and Riese, M.: Tomographic retrieval approach for mesoscale gravity wave observations by the PREMIER Infrared Limb-Sounder, Atmos. Meas. Tech., 3, 339-354, https://doi.org/10.5194/amt-3339-2010, 2010.

Ungermann, J., Blank, J., Lotz, J., Leppkes, K., Hoffmann, L., Guggenmoser, T., Kaufmann, M., Preusse, P., Naumann, U., and Riese, M.: A 3-D tomographic retrieval approach with advection compensation for the air-borne limb-imager GLORIA, Atmos. Meas. Tech., 4, 2509-2529, https://doi.org/10.5194/amt-4-25092011, 2011.

Ungermann, J., Pan, L. L., Kalicinsky, C., Olschewski, F., Knieling, P., Blank, J., Weigel, K., Guggenmoser, T., Stroh, F., Hoffmann, L., and Riese, M.: Filamentary structure in chemical tracer distributions near the subtropical jet following a wave breaking event, Atmos. Chem. Phys., 13, 10517-10534, https://doi.org/10.5194/acp-13-10517-2013, 2013.

von Clarmann, T., De Clercq, C., Ridolfi, M., Höpfner, M., and Lambert, J.-C.: The horizontal resolution of MIPAS, Atmos. Meas. Tech., 2, 47-54, https://doi.org/10.5194/amt-2-47-2009, 2009.

Weigel, K., Hoffmann, L., Günther, G., Khosrawi, F., Olschewski, F., Preusse, P., Spang, R., Stroh, F., and Riese, M.: A stratospheric intrusion at the subtropical jet over the Mediterranean Sea: air-borne remote sensing observations and model results, Atmos. Chem. Phys., 12, 8423-8438, https://doi.org/10.5194/acp-12-8423-2012, 2012.

Wyoming Atmospheric Soundings website: Department of Atmospheric Science, University of Wyoming, USA, available at: http://weather.uwyo.edu/upperair/sounding.html, last access: 10 October 2018. 